\title{
Modelo para la continuidad de la formación de grado en posgrado: UNAN-Managua
}

\section{Model for the continuity of graduate education in postgraduate training: UNAN-Managua}

\author{
Escobar Soriano, Álvaro Antonio; de Armas, Roberto
}

\author{
(iD Álvaro Antonio Escobar Soriano \\ aescobar@unan.edu.ni \\ Universidad Nacional Autónoma de Nicaragua, \\ Managua , Nicaragua \\ iD Roberto de Armas \\ rdearmas45@yahoo.es \\ Universidad de la Habana, Cuba, Cuba
}

Revista Torreón Universitario

Universidad Nacional Autónoma de Nicaragua-Managua, Nicaragua

ISSN: $2410-5708$

ISSN-e: 2313-7215

Periodicidad: Cuatrimestral

vol. 10 , núm. 28,2021

revis.torreon.faremc@unan.edu.ni

Recepción: 11 Agosto 2020

Aprobación: 06 Abril 2021

URL: http://portal.amelica.org/ameli/
jatsRepo/387/3872112001/index.html

DOI: https://doi.org/10.5377/rtu.v10i28.11522

El autor o los autores de los artículos, ensayos o investigaciones conceden a la Universidad Nacional Autónoma de Nicaragua, Managua (UNAN-Managua) los derechos de edición (copyright) del trabajo enviado, por consiguiente la Universidad cuenta con el derecho exclusivo para publicar el artículo durante el periodo completo de los derechos de autor.

\section{c) (i) () $\ominus$}

Esta obra está bajo una Licencia Creative Commons AtribuciónNoComercial-SinDerivar 4.0 Internacional.
Resumen: La continuidad de la formación de grado en posgrado tiene la meta de integrar los procesos de formación, investigación y extensión universitaria en una secuencia coherente, de mayor alcance de continuidad de competencias de grado hacia posgrado, que permita la vinculación y el desarrollo efectivo de las líneas de investigación en ambos niveles. Por tanto, para alcanzarlo es necesaria una metodología de trabajo constructiva, recursiva, sistemática y de participación inclusiva de los actores involucrados.

Para ello, la construcción de un modelo para la continuidad de la formación de grado en posgrado explique cómo se puede vincular la formación de grado y posgrado tiene sus bases en diferentes fundamentos. Entre estas se encuentran: la metodología para construir modelos teóricos, el marco legal del país, la misión, visión y valores de la institución de educación superior, además en conceptos y teorías relacionados con modelos curriculares que favorecen el desarrollo integral de los aprendizajes, de los procesos de investigación y de extensión.

Los diferentes niveles de integración (nivel de integración en la carrera de grado, nivel de integración en el eje integrador, proyectos de investigación (de intervención) y nivel de integración y vinculación con posgrado), dan coherencia al proceso de continuidad en el que se vinculan la formación, la investigación y la extensión. No obstante, el modelo se concretiza finalmente en una serie de acciones que culminan con la mejora de la formación de los programas de posgrado, tomando como base el modelo para desarrollar competencias.

Palabras clave: modelo, integración, formación en competencias, investigación, extensión.

Abstract: The continuity of postgraduate undergraduate training has the goal of integrating university training, research and extension processes in a coherent sequence, of greater scope and continuity of skills from undergraduate to postgraduate, which allows the linkage and effective development of lines of research at both levels. Therefore, to achieve this, a constructive, recursive, systematic work methodology and inclusive participation of the actors involved is necessary.

To do this, the construction of a model for the continuity of undergraduate and graduate training explains how undergraduate and graduate training can be linked is based on different foundations. Among these are: the methodology 


\begin{abstract}
to build theoretical models, the country's legal framework, the mission, vision and values of the institution of higher education, as well as concepts and theories related to curricular models that favor the integral development of learning, of research and extension processes.

The different levels of integration (level of integration in the undergraduate degree, level of integration in the integrating axis, research projects (intervention) and level of integration and link with postgraduate degrees), give coherence to the continuity process in which the they link training, research and extension. However, the model is finally materialized in a series of actions that culminate in the improvement of the training of postgraduate programs, taking as a basis the model to develop competencies.
\end{abstract}

Keywords: model, integration, skills training, research, extension.

\title{
I. INTRODUCCIÓN
}

La continuidad en la formación de grado en posgrado en las universidades que buscan ingresar en la nueva sociedad del conocimiento es una necesidad para el desarrollo del conocimiento científico y la mejora de los conocimientos de los profesionales. Con el MODELO PARA LA CONTINUIDAD DE LA FORMACIÓN DE GRADO EN POSGRADO se favorecerá la transferencia de conocimientos desde las diferentes áreas del saber y niveles de formación, es decir los resultados de la acción integrada inter y transdisciplinar de la formación, la investigación y la extensión se trasladarán no solo a lo interno de la institución, sino hacia la sociedad nicaragüense. Con esto, se podrá ayudar a resolver problemas educativos, científicos, técnicos, económicos y sociales puestos en la palestra pública por los principales actores del país: sus ciudadanos.

En consecuencia, la continuidad de la formación de grado en posgrado tiene como objetivo: "Integrar los procesos de formación, investigación y extensión universitaria en una secuencia coherente mayor alcance y de continuidad de competencias de grado hacia posgrado, que permita la vinculación y el desarrollo efectivo de las líneas de investigación en ambos niveles”. Por tanto, para alcanzarlo es necesaria una metodología de trabajo constructiva, recursiva, sistemática y de participación inclusiva de los actores involucrados.

La transformación de las IES en países en vías de desarrollo de Latinoamérica es un proceso alcanzable y necesario para el mejoramiento de la educación de las sociedades. Por ello, es necesario no solo pensar en un rediseño de su funcionamiento, sino en un perfeccionamiento de su quehacer, mediante la transformación de los currículos actuales en un modelo de actuación docente que favorezca la mejora continua tanto de los procesos curriculares como de los procesos de investigación.

Lo anterior se logrará a través de la integración de los saberes, de los objetivos de aprendizaje (resultados de aprendizaje), de los procesos de investigación, de los procesos de extensión, de los marcos competenciales, de tal manera que se actúe sobre la base de indicadores alcanzables, medibles, evaluables, que permitan una continuidad sostenida y coherente entre los niveles de grado y posgrado. 


\section{OBJETIVOS DEL MODELO}

\subsection{Objetivo General}

Integrar los procesos de formación, investigación y extensión universitaria en una secuencia coherente, de mayor alcance y de continuidad de competencias de grado hacia posgrado, que permita la vinculación y el desarrollo efectivo de las líneas de investigación en ambos niveles.

\subsection{Objetivos específicos}

- Fomentar la construcción e implementación de currículos de grado y posgrado, con la integración, la flexibilidad y la continuidad como categorías de acción, que coadyuven a la resolución de problemas sociales relacionados con el contexto nacional, regional y mundial.

- Desarrollar competencias científicas, investigativas e innovadoras, mediante procesos de docencia, investigación y extensión que consoliden los procesos de aprendizaje de los estudiantes de grado en la ruta de continuidad de estudios hacia posgrado.

- Fomentar prácticas integradoras de formación profesional en las que se demuestren valores y actitudes creativas, innovadoras y emprendedoras, desde las perspectivas social, económica y ecológica, de acuerdo con el contexto nacional, regional y mundial.

- Promover la inteligencia emocional, autorregulación, estilos de vida saludables, comunicación asertiva, efectiva y el trabajo colaborativo para la planificación, ejecución, control, evaluación crítica y autocrítica de las actividades de docencia, investigación y extensión en diferentes contextos de actuación profesional.

\section{Metodología de construcción}

Un modelo es una representación que pretende reformular un suceso o fenómeno a ser explicado. Este requiere de un marco teórico que permita interpretarlo como punto de partida para poder construirlo y luego poder aplicarlo, a fin de poder observar y teorizar sobre su funcionamiento, por tanto, predecir los resultados de esa confrontación con el fenómeno de la realidad en estudio. (Lahitte, Hurrei y Malpartida,1989).

Para la construcción del modelo para la continuidad de la formación de grado en posgrado, se ha considerado como referente principal la metodología planteada por, Fontaines - Ruiz y Martínez (2015). Para ellos, un modelo teórico representa tramas (concepto y teorías) que permiten la comprensión de la composición y funcionamiento de los objetos de estudios. En ese proceso de representación, la textura denota la intra, inter y transrelación de estadios de mayor a menor complejidad y abstracción, que aterriza en el terreno de lo empírico, donde tiene sentido el modelo en relación con el comportamiento natural que este intenta representar.

Por tanto, ambos autores consideran que modelizar es una invitación a recorrer las profundidades diacrónicas y sincrónicas del objeto, a fin de poder explicar el nivel de conocimiento logrado sobre este. Para ello, es necesario seleccionar conceptos claves desde donde sea posible tejer redes de hipótesis, contrastarlas con el objeto y producir el conjunto de ideas desde donde se comprenda ¿quién o qué es x?, ¿de qué está hecho $\mathrm{x}$ ?, $\mathrm{y}$ ¿cómo funciona y funcionará $\mathrm{x}$ ?, a decir, concebir desde esta base las predicciones sobre el objeto de estudio dentro de la realidad observada.

Construir un modelo teórico requiere elaborar una estructura y una rutina de construcción que permita darle orden y coherencia al discurso, para ello se proponen los siguientes pasos: 
- Definición de los planos de expresión de los conceptos que constituyen el entramado semántico de la red teórica. Cada idea o concepto lleva implícito un nivel de complejidad y abstracción que acerca o aleja al interlocutor de la posibilidad de comprenderlo: nivel teórico - abstracto (se expresan los conceptos centrales, no pueden ser observados a simple vista, de su derivación e interrelación depende la posibilidad de explicar los elementos bajo estudio), nivel derivado de primer orden (permite extraer las partes del todo, los conceptos no se pueden hacer tangibles rápidamente, porque no son observables, pero son menos complejos que los del plano abstracto) y nivel derivado de segundo orden (permite identificar con mayor claridad los conceptos involucrados en sus funcionamiento, por tanto tiene un nivel de abstracción muy cercano al mundo observable donde convergen los conceptos abstractos y sus derivaciones).

- Establecimiento de las relaciones suscitadas entre los diferentes conceptos teóricos y sus planos de expresión. Estas ocurren dentro de un mismo plano (relación de un mismo plano de abstracción, consolidando el sentido entre los conceptos, a fin de que no desvirtúen su esencia ni la esencia del modelo) o entre ellos (estas relaciones ocurren entre el plano abstracto y derivados debido a los niveles de comunicación a lo interno de cada uno o entre ellos, establecen definiciones y componentes del modelo que serán contrastados con la realidad, a fin de falsarlo (Lakatos, 1978) y retroalimentarlo.

- Expresión de los conceptos y sus sistemas de derivación. Se desmontan los factores o conceptos que conforman el modelo con el fin de definir la comunicación inter e intraplanos. En este paso de la rutina, se recomienda conceptualizar y caracterizar a cada agente o factor que incide en el modelo para evitar probables contradicciones que puedan ocurrir.

- La estructuración formal del modelo. Se construye mediante una especie de módulos interdependientes, que se establecen como un todo integrado a partir del cual se construye cada parte, teniendo presente la lógica de sentido establecida a lo largo de la investigación del objeto de estudio.

La pertinencia de esta metodología de construcción de modelos teóricos, se basa en la necesidad de refinar un camino para poder interpretar el flujo comunicacional establecido entre los diferentes conceptos seleccionados y la producción de nuevas estructuras teóricas con diferentes niveles de abstracción, que puedan ser observables en el plano empírico. En los siguientes apartados, se concretiza la metódica expuesta, considerando los niveles de aproximación necesarios al objeto de estudio: el proceso de continuidad de la formación de grado en posgrado.

\section{Resultados}

\subsection{Modelo para la continuidad de formación de grado en posgrado}

Un modelo para la continuidad de la formación de grado en posgrado tiene sus bases en diferentes fundamentos. Entre estas se encuentran: la metodología para construir modelos teóricos, el marco legal del país, la misión, visión y valores de la institución de educación superior, además en conceptos y teorías relacionados con modelos curriculares que favorecen el desarrollo integral de los aprendizajes, de los procesos de investigación y de extensión.

\subsection{Fundamento legal}

Las instituciones de educación superior tienen su base legal en diferentes normas establecidas en el marco jurídico de cada país. En Nicaragua, las universidades adscritas al Consejo Nacional de Universidades funcionan bajo la Ley de Autonomía Universitaria (Ley $\mathrm{N}^{\circ} 89$ ). Esta, en su artículo 6, establece los fines y 
objetivos de la Educación Superior Nicaragüense. Estos confieren las líneas de actuación que se deben seguir para lograr una formación efectiva con valores nacionales y el desarrollo científico - técnico requerido por la universidad en su ruta de desarrollo en relación con la sociedad nicaragüense:

- Contribuir a la formación científica, técnica, cultural y patriótica de los estudiantes.

- Impulsar la superación científica, técnica, cultural y pedagógica del personal docente y la capacitación del personal administrativo.

- Vincular la formación de los estudiantes al proceso productivo y a las necesidades objetivas del desarrollo económico, en función de los intereses populares.

- Fomentar y desarrollar la investigación científica para contribuir a la transformación de la sociedad y mejoramiento y adaptación de nuevas tecnologías.

- Propiciar la capacidad crítica y autocrítica, cultivando en el estudiante la disciplina, la creatividad, el espíritu de cooperación y la eficiencia, dotándolo de sólidos principios morales, cívicos y humanísticos.

- Organizar la Proyección Social, la Difusión Cultural y la Extensión Universitaria en beneficio del pueblo.

- Difundir el legado de las figuras patrióticas culturales y científicas, de los héroes y mártires de los forjadores de la Nación.

\subsection{Declaraciones de acción en la cultura organizativa de las IES: misión, visión y valores.}

La misión, la visión y los valores son las principales declaraciones que una universidad tiene como ruta para la consecución de sus objetivos estratégicos. Por tanto, son una intención estratégica que engloba un futuro deseado o la aspiración motivadora (Johnson y Scholes, 2001) de los directivos, docentes - investigadores, trabajadores administrativos y estudiantes de toda la IE. Es decir, "son los cimientos en los que se sostiene su cultura, y sobre ellos ha de edificarse todo lo demás”. (Aznar, 2017, p. 4).

Siguiendo las ideas plateadas en el párrafo anterior, Soler (1996), comparte la idea de Harrison (1986), de que la misión refleja el fin último de la institución y los valores de las personas asociadas con el beneficio de esta, es decir es la huella que impregna la filosofía y los objetivos que permiten tomar acciones de acuerdo con las prioridades de la esta. Por tanto, las estrategias y las estructuras deben subordinarse a la misión de la universidad.

Bueno, et al (1996), considera que la misión además de conceptualizar a la organización es la manera de concretar la visión de lo que se quiere ser, lo que se quiere hacer, en qué ámbitos de actuación y en qué nivel de desarrollo se quiere estar. Por ello, es una guía o referencia de valores, responsabilidades y actividades interiorizadas y compartidas por los actores de una organización. La misión de una institución permite trabajar en una visión común para todos los actores (Mullane, 2002 y Cambell, 1997).

Por consiguiente, la visión se refiere al perfil que se desea para una institución en el futuro, en relación con otras empresas u organizaciones del contexto. Por ello, analizar el estado actual en relación con el futuro permite derivar objetivos a corto, medio y largo plazo con una intención estratégica (Martos, 2009). En consecuencia, la visión de una institución de educación superior es: "aquella que engloba el futuro deseado, o la aspiración de la organización; el sentido de descubrimiento y destino que motiva tanto a los directivos como a los trabajadores". (Johnson y Scholes, 2001).

Si la misión y visión son el núcleo central de la cultural y estratégica en una institución, los valores son la síntesis de estas. Estos son la forma en que se operacionalizan las primeras. Por tanto, todos los componentes actúan bajo una declaración moral y ética que la distingue de las demás organizaciones, que se vuelve patrones de comportamiento que son las guías para alcanzar sus objetivos en coherencia con su perspectiva cultural y estratégica. 
Los valores representan el cómo se hacen o se deben hacer las cosas en una empresa, organización o institución. Por ello, estos deben ser asumidos, interiorizados y compartidos por sus miembros, en tanto: "son aprendizajes estratégicos relativamente estables en el tiempo, (...) una forma de actuar (...) mejor que su opuesta, para conseguir que las cosas nos salgan bien”. (García y Dolan, 1997, p. 159).

Kotter y Heskett (1995), aseguran que las instituciones cuyos miembros tienen un alto grado de interiorización, aplicación y gestión compartida de los valores declarados superan, en un margen significativo, el desempeño de otras que no lo hacen. En consecuencia, ven a los valores como objetivos e intereses más importantes compartidos por la mayoría de las personas de un equipo. Lo anterior, condiciona su comportamiento, el que con frecuencia persiste en el tiempo, aunque haya reestructuración en este.

Al definir el concepto "valor", García y Dolan (1997) proponen tres dimensiones válidas para el modelo de continuidad de grado en posgrado:

- Dimensión ético - estratégica: aprendizaje de que una forma de actuar es mejor que su contraria para el logro de objetivos o metas, por ejemplo: calidad versus no calidad, el trabajo en equipo versus individualidad o la ética versus acciones fraudulentas.

- Dimensión económica: alcance y significado de las personas, ideas, actos, sentimientos o hechos que mueven a la acción exitosa en la institución: innovación, creatividad y confianza.

- Dimensión psicológica: cualidades morales que permiten, al individuo o equipos de trabajo, acometer y afrontar con valentía y sin miedo los retos institucionales.

\subsection{Líneas y objetivos estratégicos}

Las líneas y objetivos estratégicos que sirven de base a este modelo ponen en perspectiva diferentes aspectos que la universidad requiere para dar un salto cualitativo hacia la modernización, la integración de los procesos (formación, investigación y extensión), y por consiguiente, la producción de conocimiento científico que pueda transferirse hacia la formación de grado y posgrado, así como a la solución de problemas específicos prioritarios de la sociedad nicaragüense. A continuación, se presentan las líneas estratégicas que sirven de base: 
TABLA Nº1.

Líneas y objetivos estratégicos en que se basa la estrategia

\begin{tabular}{|c|c|}
\hline Líneas estratégicas & Objetivos estratégicos \\
\hline $\begin{array}{l}\text { Enseñanza con calidad } \\
\text { basado en un enfoque por } \\
\text { competencias }\end{array}$ & $\begin{array}{l}\text { Brindar una formación } \\
\text { académica integral, mediante } \\
\text { un modelo curricular por } \\
\text { competencias, en } \\
\text { correspondencia con el } \\
\text { contexto nacional de acuerdo } \\
\text { con el avance de la ciencia y la } \\
\text { tecnología. }\end{array}$ \\
\hline \multirow[t]{3}{*}{$\begin{array}{l}\text { Vinculación de la Universidad } \\
\text { con sectores sociales, } \\
\text { productivos y de servicio }\end{array}$} & $\begin{array}{l}\text { Fomentar la innovación, el } \\
\text { emprendimiento, el desarrollo } \\
\text { tecnológico, artístico y cultural } \\
\text { mediante una formación } \\
\text { integral, dinámica y } \\
\text { participativa con los sectores } \\
\text { externos a fin de atender las } \\
\text { necesidades de la sociedad. }\end{array}$ \\
\hline & $\begin{array}{l}\text { Fortalecer los sistemas de } \\
\text { comunicación interna y } \\
\text { externa para el desarrollo } \\
\text { efectivo de nuestro quehacer } \\
\text { universitario y divulgar de } \\
\text { manera efectiva y pertinente } \\
\text { nuestra identidad } \\
\text { institucional, así como los } \\
\text { conocimientos científicos y } \\
\text { técnicos desarrollados a partir } \\
\text { de investigaciones ejecutadas. }\end{array}$ \\
\hline & $\begin{array}{l}\text { Fortalecer el modelo de } \\
\text { vinculación universitaria } \\
\text { mejorando la coordinación } \\
\text { con la formación, la } \\
\text { investigación y la extensión. }\end{array}$ \\
\hline
\end{tabular}

Fuente: Hernández, I. et al. (2020). Proyecto Institucional UNAN - Managua.

\subsection{Integración de los procesos de formación, investigación y la extensión: interdisciplinariedad, multidisciplinariedad y transdisciplinariedad}

\subsubsection{Las categorias complejas}

Para comprender por qué las categorías conceptuales que se definirán en este apartado son complejas y por qué sirven de base para el modelo, se parte de la definición de disciplina propuesta por Morín (2010, p.9):

La disciplina es una categoría organizacional en el seno del conocimiento científico; ella instituye allí la división y la especialización del trabajo y ella responde a la diversidad de los dominios que recubren las ciencias. Si bien esta englobada a través de un conjunto científico más vasto, una disciplina tiende naturalmente a la autonomía, por la delimitación de sus fronteras, la lengua que ella se constituye, las técnicas que ella esta conducida a elaborar o a utilizar, y eventualmente por las teorías que le son propias.

Cuando este concepto se rompe y se traslada hacia ámbitos científicos y de formación en la actual sociedad del conocimiento y de la información, esto lo complejiza, porque la realidad ya no puede concebirse de manera unilineal y determinista, tal y como lo estructuró el positivismo nacido del cartesianismo. Siguiendo estas 
ideas, en los siguientes subapartados se definen los conceptos interdisplinariedad, multidisciplinariedad y transdisciplinariedad.

\subsubsection{Interdisciplinariedad}

La integración entre los procesos de formación, investigación y extensión requiere de la aplicación de tres conceptos que favorecen tanto el avance de las ciencias como de la enseñanza y el aprendizaje en las sociedades actuales.

La interdisciplinariedad desde la investigación es el:

Conjunto de disciplinas conexas entre sí y con relaciones definidas, a fin de que sus actividades no se produzcan en forma aislada, dispersa o fraccionada. (...) se refiere a la creación de una identidad metodológica, teórica y conceptual, de forma tal que los resultados sean más coherentes e integrados. (Política de Investigación e Innovación (2017, p. 2))

El concepto de interdisciplinariedad definido desde la formación es la relación que se establece entre dos o más disciplinas afines que apuntan a la formación de un profesional (González, Hernández, Hernández y Sanz, 2003). La interdisciplinariedad se concreta en el currículo de las carreras en el eje integrador del que se derivan los componentes curriculares integradores. Este concepto se manifiesta de las siguientes maneras en el desarrollo curricular: 
TABLA No2

Manifestaciones de la interdisciplinariedad en el currículum para desarrollar competencias

\begin{tabular}{|l|l|}
\hline Manifestación & Relación interdisciplinar \\
\hline Eje integrador & $\begin{array}{l}\text { Contribuye a que el estudiante se percate } \\
\text { de las conexiones existentes en la propia } \\
\text { ciencia y no se represente estas } \\
\text { disciplinas como obligación curricular a } \\
\text { vencer con independencia una de la otra. } \\
\text { Esta relación disciplinar se logra en el } \\
\text { plan de estudio en los componentes } \\
\text { curriculares integradores que conjuntan } \\
\text { en una acción integradora: la docencia, la } \\
\text { investigación y la extensión, la que } \\
\text { alcanza su punto más profesionalizante } \\
\text { en las prácticas de formación } \\
\text { preprofesional y de formación } \\
\text { profesional. }\end{array}$ \\
\hline Interdisciplinariedad \\
lineal & $\begin{array}{l}\text { Se logra cuando una teoría, ley, concepto } \\
\text { o regularidad tomada de una disciplina se } \\
\text { utiliza para explicar fenómenos de otra. } \\
\text { Esta relación disciplinar se manifiesta en } \\
\text { estructural }\end{array}$ \\
$\begin{array}{ll}\text { la integración que realizan los docentes en } \\
\text { la mesoplanificación semestral y } \\
\text { microplanificación diaria, cuando } \\
\text { planifican los cortes evaluativos } \\
\text { integradores y conciben las Bases } \\
\text { Orientadoras de la acción que guian } \\
\text { desde la formación el actuar de futuro } \\
\text { profesional. }\end{array}$ \\
$\begin{array}{ll}\text { Ocurre cuando las interacciones entre dos } \\
\text { o más materias llevan a la creación de un } \\
\text { cuerpo de leyes nuevas que forman la } \\
\text { estructura básica de una disciplina } \\
\text { original, la cual no puede ser reducida a la } \\
\text { relación formal entre las disciplinas que la } \\
\text { generan. }\end{array}$ \\
$\begin{array}{l}\text { Esta relación se puede empezar a } \\
\text { desarrollar desde la formación de grado } \\
\text { cuando los estudiantes realizan sus } \\
\text { trabajos en el eje integrador o participan } \\
\text { en programas y proyectos de } \\
\text { investigación (grupos de investigación). } \\
\text { Debe continuar en la formación } \\
\text { posgraduada a nivel de programas } \\
\text { académicos o científicos: Maestrías y } \\
\text { Doctorados. }\end{array}$ \\
\hline
\end{tabular}

Fuente: adaptado a partir de (González, Hernández, Hernández y Sanz, 2003)

En el cuadro anterior, se logra apreciar como el concepto interdisciplinariedad definido desde las dimensiones investigación y formación se intersecan cuando se aplican a los procesos de construcción, implantación curricular y la formación de los estudiantes.

\subsubsection{La multidisciplinariedad}

La multidisciplinariedad es considerada desde la ciencia: "el conjunto de disciplinas que se proponen simultáneamente, pero sin hacer aparecer explícitamente las relaciones que pueden existir entre ellas. En este 
ámbito de investigación, las aproximaciones al objeto de estudio se realizan desde diferentes ángulos, usando diferentes perspectivas disciplinares”. (Política de Investigación e Innovación, 2017, p. 2)

Desde los procesos de formación, la categoría mutidisciplinariedad o interdisciplinariedad paralela, ocurre:

(...) cuando diversas disciplinas, confluyen en la solución de un problema concreto, sin que estas pierdan su identidad. En el marco de los planes de estudio, se sugiere reservar lo multidisciplinario para el caso de la resolución de problemas que trasciendan las disciplinas propias de un determinado perfil.

TABLA N॰3

Manifestaciones de la multidisciplinariedad en el currículum para desarrollar competencias

\begin{tabular}{|l|l|}
\hline Manifestación & Relación multidisciplinar \\
\hline $\begin{array}{l}\text { Componentes } \\
\text { integradores }\end{array}$ & $\begin{array}{l}\text { Esta relación disciplinar se logra en el } \\
\text { plan de estudio en los componentes } \\
\text { curriculares integradores que conjuntan } \\
\text { en una acción integradora: la docencia, } \\
\text { la investigación y la extensión. } \\
\text { Estos componentes pueden finalizar con } \\
\text { estrategias integradoras que exigen como } \\
\text { producto un trabajo final de curso como } \\
\text { obligación curricular. } \\
\text { Los estudiantes de diferentes carreras } \\
\text { pueden relacionar estos trabajos finales } \\
\text { de curso con proyectos de intervención. } \\
\text { Para ello, se requiere la correspondiente } \\
\text { coordinación previa entre las distintas } \\
\text { carreras para asegurar la simulación o } \\
\text { realización en vivo de estas actividades. }\end{array}$ \\
$\begin{array}{l}\text { Son acciones que integran estudiantes y } \\
\text { docentes - investigadores con el fin de } \\
\text { brindar ayuda a la sociedad, en especial } \\
\text { a comunidades desfavorecidas donde se } \\
\text { requiere la concurrencia de diferentes } \\
\text { profesiones y profesionales: docentes, } \\
\text { ingenieros, médicos, enfermeras, } \\
\text { trabajadores sociales, abogados entre } \\
\text { otros, con el fin de cooperar, ofreciendo } \\
\text { posibles soluciones a problemáticas } \\
\text { sentidas por sus pobladores. }\end{array}$ \\
\hline Proyecto de \\
intervención
\end{tabular}

Fuente: adaptado a partir de (González, Hernández, Hernández y Sanz, 2003)

La manifestación de la multidisciplinariedad debe promoverse desde los primeros años del proceso de formación profesional. Es necesario que los estudiantes de las carreras desarrollen experiencia sobre cómo actúan o se desempeñan profesiones diferentes de la propia, a fin de: escuchar, comprender, entender, analizar y juzgar el lenguaje de otras profesiones o expresarse, defender y aportar sus ideas desde su formación. Lo anterior, es la manera cómo desde un currículo por competencias, que vincula líneas de investigación y profesiones diversas, se aporta tanto a la formación como a la solución de problemas desde diferentes miradas $\mathrm{y}$ acciones profesionales.

\subsubsection{La transdisciplinariedad}

La ciencia considera la transdisciplinariedad como: 
la coordinación de todas las disciplinas sobre la base de una axiomática general introducida a todos los niveles, a partir del nivel de los objetivos. En este ámbito se refiere al proceso en el cual ocurre la convergencia entre disciplinas, acompañado por una integración mutua de las epistemologías disciplinares. (Política de Investigación e Innovación (2017, p. 2)).

Se completa la definición anterior con la idea de que la coordinación entre las disciplinas no solo se da en el ámbito de los laboratorios o centros de investigación, sino que esta ocurre en el sistema de enseñanza (Tamayo y Tamayo, 2004) de las diferentes carreras. Por consiguiente, el proceso de formación considera que la transdisciplinariedad ocurre "cuando varias disciplinas interactúan mediante la adopción de una disciplina que opera como nexo común” (González, Hernández, Hernández y Sanz, 2003, p. 148), integrando en un nivel superior objetivos múltiples orientados hacia una finalidad común de los sistemas.

TABLA N 4

Manifestaciones de la transdisciplinariedad en el currículum para desarrollar competencias

\begin{tabular}{|l|l|}
\hline Manifestación & Relación transdisciplinar \\
\hline $\begin{array}{l}\text { Procesos de } \\
\text { producción o de } \\
\text { innovación }\end{array}$ & $\begin{array}{l}\text { En el plan de estudio de las carreras, se } \\
\text { pueden encontrar procesos de } \\
\text { producción o de innovación, atravesados } \\
\text { o permeados por todas las disciplinas del } \\
\text { plan de estudio. }\end{array}$ \\
\hline Ejes disciplinares & $\begin{array}{l}\text { Un eje disciplinar determinado puede ser } \\
\text { transdisciplinar en los planes de estudio } \\
\text { de determinadas carreras, porque su } \\
\text { aporte tiene una presencia y un carácter } \\
\text { utilitario en la mayoria de las disciplinas } \\
\text { que conforman la formación de ese } \\
\text { profesional. }\end{array}$ \\
\hline $\begin{array}{l}\text { Proyecto de } \\
\text { intervención }\end{array}$ & $\begin{array}{l}\text { Son acciones que integran estudiantes y } \\
\text { docentes - investigadores con el fin de } \\
\text { brindar ayuda a la sociedad, en especial } \\
\text { a comunidades desfavorecidas donde se } \\
\text { requiere la concurrencia de diferentes } \\
\text { profesiones y profesionales: docentes, } \\
\text { ingenieros, médicos, enfermeras, } \\
\text { trabajadores sociales, abogados entre } \\
\text { otros, con el fin de cooperar ofreciendo } \\
\text { posibles soluciones a problemáticas } \\
\text { sentidas por sus pobladores. }\end{array}$ \\
\hline
\end{tabular}

Fuente: adaptado a partir de (González, Hernández, Hernández y Sanz, 2003)

Torres (1987) considera que la transdisciplinariedad es el nivel superior de interdisciplinariedad. Por tanto, con esta integración se busca desaparecer las fronteras entre las diversas disciplinas, sobrepasando las relaciones e interacciones entre estas, a fin de lograr un ideal de unificación epistemológico, cultural y subjetivo en los procesos de investigación, formación y extensión universitaria. Por ello, los planes de estudio deben responder a una red variada y compleja de nuevos sectores híbridos, que rompen la lógica fragmentada y unilineal de los planes de estudio formales productores de profesionales monodisciplinarios. En consecuencia, las nuevas carreras generan profesionales transgresores de fronteras capaces de aportar soluciones a problemáticas sociales complejas desde una visión integrada e integradora, inicialmente, considerada difícil de lograr por los equipos de académicos. 


\subsubsection{Otras categorias complejas}

\subsubsection{Ciencia}

El concepto de ciencia para Martínez (2010, p.20), se aplica: “tanto para identificar el proceso de elaboración de los conocimientos científicos, como para todo el sistema de conocimiento comprobado en la práctica, que constituye una verdad objetiva, y también para distinguir las esferas del conocimiento científico, esto es, las diferentes ciencias".

Así, las ciencias son un sistema de conocimiento en desarrollo, generado por los correspondientes métodos cognitivos que reflejan la comprensión de la realidad en conceptos cuya veracidad se comprueba o se demuestra a través de la práctica científica y la práctica social.

Las ciencias modernas son un conjunto de ramas extraordinariamente subdividido. De ahí que podamos decir que la ciencia es conocimiento en constante evolución (Ortiz y Del pilar, 2007). Por ello, para poder incursionar en el mundo científico actual las unidades académicas integradas en las carreras y centros de investigación deben romper con la idea de ciencias con desarrollos disciplinares aislados para incorporar la cultura de una ciencia interdisciplinar capaz de producir valores científicos desde la investigación aplicada.

\subsubsection{La investigación cientifica}

Desde una visión compleja de la realidad, investigar es relacionar, injertar, contaminar, analizar coyunturas, acercarse o traspasar los umbrales de las disciplinas. Por consiguiente, la investigación reconoce logros, pero le da preeminencia al ruido, a las tensiones, a las incertidumbres, a las fallas estructurales, a la ruptura, a la entropía y a la negación del método único.

La investigación científica es una actividad y un proceso de búsqueda de conocimiento nuevo que involucra diversas categorías importantes. Esta permite manejar los métodos y procesos metodológicos establecidos en cada área del conocimiento, derivados de las experiencias y conocimientos previos, que solo la investigación de la realidad puede aportar.

Por tanto, el saber científico es producto de procesos de investigación que pasan de lo estrictamente teórico a lo concreto para recolectar los datos de manera empírica y someterlos al análisis teórico. Coincidiendo con Ortiz y Del pilar (2007), si los conocimientos tienen una aplicación práctica para el bienestar humano, se puede decir que estamos hablando de ciencias aplicadas, las que vistas desde la interdisciplinariedad y la transdisciplinariedad pueden aportar soluciones a situaciones complejas en los ámbitos social, económico, científico y técnico.

\subsubsection{Grupo de investigación}

Un grupo de investigación es el conjunto de personas que investiga en una temática dada, formula uno o varios problemas de su interés, traza un plan estratégico (proyecto formal) de largo o mediano plazo y produce nuevos resultados de conocimiento sobre el tema en cuestión (Martínez, 2010). La existencia de un grupo de investigación se demuestra con los resultados de su trabajo los cuales son verificables y criticables por la comunidad científica local, regional y mundial.

Los grupos de investigación son disciplinares, interdisciplinares y cooperan con otros grupos generando la integración de conocimiento multidisciplinar y transdisciplinar, a fin de comprender la realidad y aportar soluciones a problemáticas científicas, sociales y técnicas.

Para la formalización de un grupo de investigación se requiere que este: 
- Cree un plan estratégico que proyecte su trabajo.

- Elabore un plan de trabajo estratégico que involucre: misión, visión, reglamento de ética, área de saber, líneas y sublíneas de investigación, problemas que aborda, áreas de actuación, productos que generará, aplicabilidad e impacto de sus productos, sistemas de transferencia, viabilidad, comunicación y validación del conocimiento generado, cronograma de trabajo, integrantes (tanto docentes - investigadores, estudiantes asociados y redes), hoja de vida de los integrantes.

- Se inscriba de manera formal en la instancia o institución correspondiente.

Esta unidad de actuación científica exige la presencia y acción de investigadores sensibles, capaces de percibir, analizar e interpretar los fenómenos, sus constantes, para traducirlas en teoría aplicable en las condiciones similares. Para poder cumplir con su plan de trabajo y sus proyectos de investigación, este requiere de disciplina y responsabilidad para que su trabajo genere productos de alta calidad.

El liderazgo y la responsabilidad en la investigación es una condición en la que los actores cumplen papeles de líder, acompañante y apoyo. En un grupo de investigación, los integrantes participan como:

- Investigador principal: quien es el responsable directo del grupo y su representante legal. Es el investigador con más trayectoria y formación. Se encarga de analizar interpretar y redactar, producir o avalar los resultados de los proyectos en ejecución o terminados.

- Coinvestigador: acompaña al grupo en igual rango que el principal, pero que realiza actividades bajo su tutela dadas las características del proyecto específico que se desarrolle.

- Investigador auxiliar: apoya actividades de tipo instrumental bajo la supervisión del investigador principal o coinvestigador. Sus actividades pueden ser de recopilación de información, ordenamiento y procesamiento de datos, asistentes de laboratorio, actividades administrativas.

- Investigador de campo: desarrolla actividades operativas bajo la supervisión del investigador principal o coinvestigador. Puede tomar muestras, aplicar instrumentos (en cuestas, entrevistas), redactar notas y diarios de campo.

El grupo debe tener claridad de las funciones de los investigadores, de sus responsabilidades, de su movilidad interna y externa, por ello deben estudiar, capacitarse y practicar constantemente, a fin de obtener éxito y reconocimiento en la comunidad científica, en la comunidad universitaria y en la sociedad.

\subsubsection{Proyecto de investigación}

Un proyecto de investigación es el desarrollo de actividades científicas y tecnológicas organizadas de manera sistemática mediante un plan de trabajo que orienta su acción hacia el logro del propósito o los propósitos definidos. Este involucra actores (investigadores, estudiantes, comunidades), problemáticas (científicas, tecnológicas, sociales), saberes (teorías, metodologías) y recursos (económicos, infraestructura).

\subsubsection{Redes de investigación y educación}

Referirse a las redes de investigación y educación es entrar en el proceso de transformación de la cultura investigativa y educativa en las instituciones de educación superior. Es producir nuevo conocimiento de manera competente y con valor grupal, en contraposición de la visión individualista que impera en la cultura académica de muchas universidades. Por tanto, es un proceso de colaboración local, regional y mundial que genera conocimiento colectivo mediante la comunicación de los resultados de ambas praxis que requieren acciones conjugadas y con interconectividad.

González, (2013, p. 25) reflexiona sobre las características y oportunidades de la creación de redes: 
El efecto de configuración de una red opera de forma positiva cuando adquiere propiedades que no derivan de la suma de los elementos. En ese momento comenzamos a tener un nodo, es decir, un sistema integrado y abierto con mayor resiliencia para reconfigurarse creativamente, es decir, más inteligente frente a obstáculos o situaciones inéditas.

Por tanto, las redes de investigación y educación permiten a científicos, investigadores, académicos, profesores y estudiantes colaborar, compartiendo información y herramientas metodológicas, mediante una serie de interconexiones presenciales y virtuales duraderas.

Existen diferentes tipos de redes desde el punto de vista de la educación (formación), la investigación y la extensión:

- Desde el punto de vista geográfico: redes locales (a lo interno de una universidad, interuniversitarias de un país), redes regionales (interuniversitarias entre instituciones de países pertenecientes a una misma región geográfica), intercontinentales (interuniversitarias entre instituciones de países pertenecientes a diferentes regiones geográficas), mundiales (interuniversitarias que enlazan a las universidades de todo el planeta).

- Desde el punto de vista científico y educativo: redes de acuerdo con las ramas y áreas científicas y educativas.

- Desde el punto de vista de la cantidad de instituciones y temáticas desarrolladas: se puede hablar de redes simples y complejas.

Las redes académicas tienen como propósito:

- La interconexión entre docentes e investigadores de diferentes latitudes, áreas y campos de investigación y campos educativos.

- Apoyar el trabajo de investigadores y académicos mediante la provisión de una infraestructura de comunicación de datos de gran capacidad, lo que permite la rápida transferencia de grandes cantidades de datos.

- Ser una poderosa herramienta de investigación en sí mismas, al proveer una plataforma sobre la que investigadores e innovadores pueden desarrollar y probar nuevos servicios y tecnologías de red.

Tanto los colectivos de académicos como los grupos de investigación deben hacer esfuerzos por pertenecer a diferentes redes educativas o de investigación a fin de consolidar sus proyectos de investigación desde las dimensiones: comunicación, financiamiento, reconocimiento y movilidad.

\section{Discusión}

\subsection{La integración en los currículos modernos}

La integración considerada como la articulación de las ciencias o disciplinas particulares o sectores de aproximación disciplinar, permite concebir mejores currículos contrapuestos a cualquier amalgama o yuxtaposición de asignaturas, resultado de una práctica de la enseñanza heredada de la compartimentación de los saberes, concebida por el enciclopedismo del siglo XVIII (Borrero 1982) y por la especialización producida por el proceso de industrialización iniciado en el siglo XIX (González, Hernández, Hernández y Sanz, 2003). No obstante, la disciplina tiene su origen en la universidad, tal y como lo reconoce Morín (2010):

La organización disciplinaria fue instituida en el siglo XIX, particularmente con la formación de las universidades modernas, luego se desarrolló en el siglo XX con el impulso de la investigación científica; esto quiere decir que las disciplinas tienen una historia: nacimiento, institucionalización, evolución, dispersión, etc.; esta historia se inscribe en la de la universidad que a su vez está inscripta en la historia de la sociedad. (p.9). 
Como estrategia para estructurar currículos modernos, la integración interdisciplinar y transdisciplinar genera una visión totalizadora de los fenómenos y de los problemas sociales, tal y como se dan en la vida real. Por tanto, para diseñar planes de estudio con esta visión se realizan tres tareas fundamentales: aplicar aspectos y formas de integración, selección y estructuración de los contenidos y la sistematización o globalización del currículo. Estas favorecen superar la cultura del enfoque disciplinar o por asignaturas que tiende a fragmentar el conocimiento, produciendo insuficiencias que al final desembocan en aprendizajes difusos y poco útiles para el desempeño profesional.

Los planteamientos anteriores, se relacionan con el concepto de interdisciplinariedad. Con este se persigue el apremiante y necesario vínculo entre los profesionales. Por consiguiente, la búsqueda de esta articulación entre profesiones es para producir mejores respuestas, por tanto, posibles soluciones a los problemas complejos de la realidad actual.

La integración generada por la concepción interdisciplinar del quehacer de la formación académica derivada del quehacer científico, transfiere coherencia y cohesión interna a las instituciones de educación superior. Esto hace que paulatinamente se puedan superar las fallas producidas por una concepción curricular, por tanto, de formación profesional compartimentada y disciplinarmente inconexa.

A continuación, se puede observar las vías y efectos, que produce la integración interdisciplinar en la construcción de un currículo, que vincula y transfiere saberes conectados por la necesidad de responder efectivamente a la nueva realidad mundial del conocimiento y la información:

TABLA N॰5

Vías y efectos de la integración curricular

\begin{tabular}{|c|c|}
\hline Vías de integración & Efecto de la integración \\
\hline Programas Directores & $\begin{array}{l}\text { Contribuir a garantizar un rasgo del perfil profesional que responde a las } \\
\text { exigencias del desarrollo científico-técnico de la época, como es el caso } \\
\text { del dominio de una segunda lengua extranjera, de la computación, de la } \\
\text { formación económica, etc. }\end{array}$ \\
\hline Interdisciplinariedad & $\begin{array}{l}\text { Relación y vínculo entre disciplinas afines o no para la resolución de } \\
\text { problemas profesionales. La resolución entre disciplinas se establece de } \\
\text { diferentes formas (interdisciplinariedad, multidisciplinariedad, } \\
\text { transdisciplinariedad). }\end{array}$ \\
\hline $\begin{array}{l}\text { Actividades académicas, laboral } \\
\text { e investigativa }\end{array}$ & $\begin{array}{l}\text { Tener presente en el proyecto y proceso curricular estos tres tipos de } \\
\text { actividad, inherentes a todo conocimiento y desarrollar en el estudiante } \\
\text { acciones que están presentes en estos tres tipos de actividad. Asimismo, } \\
\text { condicionar la diversidad de formas de enseñanza propias de estas } \\
\text { actividades. }\end{array}$ \\
\hline Disciplina integradora & $\begin{array}{l}\text { Prever desde los primeros momentos de formación el desarrollo de } \\
\text { habilidades profesionales previstas en el perfil. Provocar la } \\
\text { comunicación colegiada entre los docentes que intervienen en ella, para } \\
\text { una dirección científica del proceso de formación profesional. }\end{array}$ \\
\hline Módulos. Currículo integrado & $\begin{array}{l}\text { Organizar fragmentos del plan de estudio o su totalidad, en torno a } \\
\text { objetos de transformación, o problemas, o núcleos temáticos donde } \\
\text { intervengan diversas materias para su abordaje. }\end{array}$ \\
\hline $\begin{array}{l}\text { Articulación horizontal y } \\
\text { vertical }\end{array}$ & $\begin{array}{l}\text { Prever objetivos a lograr a nivel de año o nivel y prever objetivos que } \\
\text { apunten a uno o varios objetivos del perfil mediante disciplinas. }\end{array}$ \\
\hline $\begin{array}{l}\text { Espacios curriculares de } \\
\text { entrenamiento profesional }\end{array}$ & $\begin{array}{l}\text { Prever segmentos curriculares, donde en torno a tareas profesionales } \\
\text { identificadas intervengan varias asignaturas o materias y el estudiante se } \\
\text { entrene en la resolución de problemas, mediante el trabajo en equipo. Se } \\
\text { plantea como alternativa o espacio curricular breve y dinámico. Puede } \\
\text { ocupar el espacio de las "holguras" a preverse en el plan de estudio. }\end{array}$ \\
\hline
\end{tabular}


Fuente: tomado de (González, Hernández, Hernández y Sanz, 2003).

Si un currículo debe manifestar la integración mediante las vías y efectos presentados en el cuadro anterior, entonces, de este se deriva:

- Prever y realizar actividades para que el estudiante se entrene en asumir el papel de líder o de subordinado.

- Hacerle seleccionar sistemáticamente entre varias alternativas una, y defenderla como la más conveniente.

- Entrenarlo para que tome decisiones y argumente.

- Entrenar al estudiante para la resolución de problemas profesionales, a lo largo de su carrera.

- Entrenarlo para trabajar en equipos multidisciplinarios, a entender el lenguaje de otro profesional y elaborar y defender informes con esta visión.

- Enfrentarlo a situaciones problemáticas nuevas y confrontarlo a un proceso de búsqueda y a una solución que resulte novedosa

- Conducirlo a llegar a resultados y publicarlos en un artículo científico.

- Provocar al estudiante para que tenga necesidad de orientarse y obtener nuevos conocimientos, de manera independiente.

- Hacer que el estudiante demuestre sus competencias en las diferentes materias, no como obligación curricular, sino como parte inherente de su futuro quehacer profesional.

En consecuencia, González, Hernández, Hernández y Sanz (2003, p. 152 - 153), consideran que se debe dar la oportunidad a estos, durante el proceso de formación, para que participen en acciones en las que se integren, según las maneras señaladas en este apartado, teniendo como referente los tres procesos con los cuales lograrán desempeños habilitantes para ser profesional:

- La actividad académica:

- Es esencialmente orientadora y modelizante.

- Se desarrolla fundamentalmente en el contexto áulico, en la institución docente.

- Como forma organizativa, se desarrolla según los distintos tipos de clases.

- Requiere como orientador indispensable al profesor con un carácter presencial o no en función de la modalidad de estudio.

- En la actividad laboral:

- Se modela, se simula y se ejecuta, la actividad profesional, a través de sus tareas particulares.

- Se sitúa al estudiante en condiciones concretas de realización.

- Como forma organizativa, se desarrolla fundamentalmente según la práctica laboral, donde no solo interviene el profesor, sino también los profesionales y técnicos del centro laboral donde se ejecute.

- Se desarrolla también intramuros; según seminarios, talleres, prácticas de laboratorio, donde se simula un proceso productivo, o se simplifica un problema profesional, para inter o multidisciplinariamente analizar y ofrecer alternativas de solución.

- Se entrena así al estudiante a trabajar en equipo, en la toma de decisiones, en la comunicación oral y escrita, en la autoformación, en la búsqueda e investigación de soluciones a Problemas Profesionales.

- La actividad investigativa:

- Se ha establecido como rasgo específico de la actividad profesional. 
- Presupone no sólo la aplicación formal de un método de investigación sino el entrenamiento en los procesos de búsqueda de la información científico-técnica, de comprobación de conjeturas, de auto controlar la actividad.

- Se desarrolla a partir de problemas profesionales a resolver y como actividad extracurricular

- Favorece el trabajo en equipo intra, multi, inter y transdisciplinario.

\subsection{Modelo para desarrollar competencias}

En el flujograma de procesos, se puede visualizar el modelo para desarrollar competencias. Este es la base sobre la cual se articula la estrategia de continuidad de estudios de grado hacia posgrado.

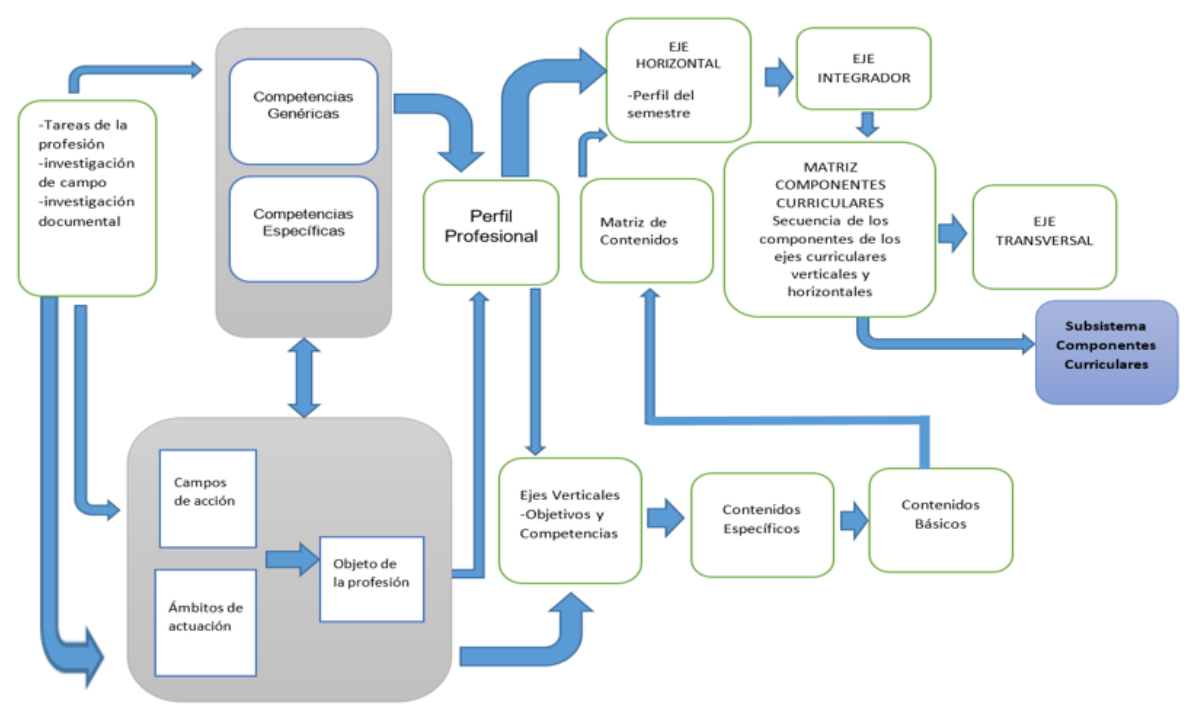

IMAGEN Nº1

Modelo para desarrollar competencias.

Fuente: Sampaio, L. Leite, P. y De Armas, R. (2015)

\subsubsection{Momentos del modelo para desarrollar competencias}

El modelo para desarrollar competencias se desarrolla en varios momentos, que tienen como características fundamentales la sistematicidad, la integración y la teoría de la acción. A continuación, se sintetiza cada momento. La elaboración del perfil profesional requiere de una serie de componentes que permiten tener un constructo que refleja el objeto de estudio de la profesión y las competencias que se deben desarrollar para poderlo dominar. 
TABLA $\mathrm{N}^{\circ} 6$.

Conceptos que intervienen en la construcción del perfil profesional

\begin{tabular}{|l|l|}
\hline \multicolumn{1}{|c|}{ Conceptos } & \multicolumn{1}{c|}{ Definiciones } \\
\hline Tareas de la profesión & $\begin{array}{l}\text { Las tareas de la profesión son las acciones esenciales, generales o especificas que } \\
\text { realiza el profesional y le permite enfrentar los problemas que se le presentan en } \\
\text { los escenarios de desempeño laboral. }\end{array}$ \\
\hline Campo de acción & $\begin{array}{l}\text { Esto son las acciones esenciales que caracterizan la profesión, y que permiten } \\
\text { visualizar las competencias que definen al futuro graduado }\end{array}$ \\
\hline $\begin{array}{l}\text { Ámbito de actuación } \\
\text { (esfera de actuación) }\end{array}$ & $\begin{array}{l}\text { Los ámbitos de actuación de la profesión se definen como los ambientes laborales, } \\
\text { en donde se desempeña el profesional. }\end{array}$ \\
\hline Objeto de la profesión & $\begin{array}{l}\text { Está interrelacionado con las tareas del profesional, los campos de acción y los } \\
\text { ámbitos de actuación y está asociado al perfil profesional. Se refiere al objeto } \\
\text { sobre el cual ejerce la acción el profesional para transformarlo. }\end{array}$ \\
\hline $\begin{array}{l}\text { Competencias de la } \\
\text { carrera }\end{array}$ & $\begin{array}{l}\text { Son "la capacidad de poner en práctica una forma integrada y dinámica } \\
\text { conocimientos, habilidades, actitudes y valores para enfrentar la solución de } \\
\text { problemas de la vida sean estos de carácter personal, profesional o social" }\end{array}$ \\
\hline $\begin{array}{l}\text { Competencias } \\
\text { genéricas }\end{array}$ & $\begin{array}{l}\text { Estas consisten en conocimientos, habilidades y actitudes necesarias en diversas } \\
\text { profesiones. Es decir, tienen carácter transferible. Debido a su relevancia, las } \\
\text { competencias genéricas son definidas por la universidad en respuestas a las } \\
\text { necesidades de la sociedad. } \\
\text { Estas competencias se integran de forma transversal en los componentes } \\
\text { curriculares (asignaturas), que incluyen los ejes integradores. }\end{array}$ \\
\hline $\begin{array}{l}\text { Pompetencias } \\
\text { especificas } \\
\text { carrera }\end{array}$ & $\begin{array}{l}\text { Resultan necesarias para dominar un conocimiento, para luego aplicarlo en una } \\
\text { disciplina o área concreta. Son aquellas que están relacionadas con las tareas de } \\
\text { la profesión y las especificidades propias de un campo de estudio. }\end{array}$ \\
\hline $\begin{array}{l}\text { Se encuentran implícitos los campos de acción, los ámbitos de actuación y las } \\
\text { competencias necesarias para la actuación profesional y ciudadana. }\end{array}$ \\
\hline
\end{tabular}

Fuente: Tomado de Sampaio, Leite y de Armas (2015).

El siguiente momento es la construcción de los ejes curriculares. Del perfil profesional de la carrera se derivan los ejes curriculares verticales y horizontales. Los ejes curriculares permiten la integración de los diferentes componentes curriculares. Para la construcción de los ejes curriculares, se debe analizar cuáles serán los contenidos que se desarrollarán en la formación profesional de cada carrera. Además, se requiere definir cuál será su distribución en el tiempo o periodo de la formación, los conocimientos (aprendizaje) que se pretenden alcanzar con el estudiante, en relación con las estrategias de enseñanza y de evaluación. 
TABLA $\mathrm{N}^{\circ} 7$

Conceptos que intervienen en la construcción los ejes curriculares

\begin{tabular}{|c|c|}
\hline Conceptos & Definiciones \\
\hline Ejes verticales & $\begin{array}{l}\text { Los ejes verticales se clasifican en ejes básicos, ejes profesionalizantes y los ejes } \\
\text { integradores. Los dos primeros son ejes temáticos verticales en los que se establecen } \\
\text { aquellos contenidos básicos y profesionalizantes, que aportan al desarrollo paulatino } \\
\text { de las competencias, ya que buscan la integración de los saberes. }\end{array}$ \\
\hline Ejes básicos & $\begin{array}{l}\text { Reúnen todos aquellos contenidos base que ayudarán al desarrollo de los ejes } \\
\text { profesionalizantes y serán nombrados de acuerdo con la naturaleza de las ciencias } \\
\text { básicas. }\end{array}$ \\
\hline $\begin{array}{l}\text { Ejes } \\
\text { profesionalizantes }\end{array}$ & $\begin{array}{l}\text { Se derivan del perfil profesional y del objeto de la profesión. Son todos aquellos } \\
\text { contenidos que van integrando saberes específicos a la carrera, los que permitirán al } \\
\text { estudiante contextualizarse con su formación profesional. }\end{array}$ \\
\hline Eje integrador & $\begin{array}{l}\text { Se logra la integración total del componente curricular. Esta es de tipo } \\
\text { interdisciplinar, y ocurre tanto en lo horizontal como en lo vertical, a lo interno de la } \\
\text { disciplina y entre disciplinas, a medida que el estudiante evoluciona en su formación. } \\
\text { En los ejes integradores se operativizan las funciones docencia, investigación y } \\
\text { extensión, por lo que deben considerarse ejes de metodología para la acción, definida } \\
\text { como una actividad Investigativa laboral integradora. } \\
\text { Por otra parte, los ejes integradores se desarrollan desde el inicio de la formación } \\
\text { profesional. En estos se integra la investigación y la práctica de formación profesional } \\
\text { hasta la culminación de los estudios. Las actividades de investigación laboral se deben } \\
\text { desarrollar a través de proyectos, prácticas profesionales, estudios de caso, } \\
\text { simulaciones, resolución de problemas reales y contextualizados, entre otras } \\
\text { estrategias didácticas. }\end{array}$ \\
\hline Ejes Horizontales & $\begin{array}{l}\text { Los ejes horizontales favorecen en el estudiante la integración de los saberes } \\
\text { adquiridos en un período de tiempo. Por ello, la comisión curricular y el colectivo de } \\
\text { académicos deben definir los objetivos de aprendizaje integradores que se han de } \\
\text { lograr en cada año y semestre, para alcanzar el desarrollo de las competencias. }\end{array}$ \\
\hline $\begin{array}{l}\text { Ejes Transversales } \\
\text { (estrategias } \\
\text { transversales } \\
\text { integradoras) }\end{array}$ & $\begin{array}{l}\text { Este tipo de ejes es considerado una estrategia curricular que permite alcanzar } \\
\text { aquellos aprendizajes que no aparecen directamente relacionados con los contenidos } \\
\text { en la integración de los ejes verticales y horizontales y abonan al desarrollo de } \\
\text { competencias genéricas y los valores institucionales, profesionales y ciudadanos. El } \\
\text { aprendizaje que se desarrolla en estos debe ser contextualizado y abordado en varios } \\
\text { componentes curriculares, inclusive en el eje integrador, sin ser necesariamente } \\
\text { formulados como una componente curricular. }\end{array}$ \\
\hline Temas transversales & $\begin{array}{l}\text { Además de las competencias genéricas, es necesario que las carreras desarrollen en } \\
\text { los ejes curriculares (transversales) los valores institucionales. La formación en } \\
\text { valores se debe promover en todos los componentes curriculares y ejes curriculares y } \\
\text { esta se logrará en todos los momentos de integración. } \\
\text { Dentro de los temas que pueden ser desarrollados de manera transversales están: la } \\
\text { innovación, emprendimiento, medio ambiente, comunicación, formación } \\
\text { humanística, valores institucionales, TIC, investigación, universidad saludable, } \\
\text { gestión de riesgo, multiculturalidad, idioma extranjero, género, entre otros. En el caso } \\
\text { de la estrategia transversal, idioma extranjero, ésta será fomentada en los diferentes } \\
\text { componentes curriculares a nivel de comprensión lectora en los campos de la } \\
\text { profesión. }\end{array}$ \\
\hline
\end{tabular}

Fuente: Tomado de Sampaio, Leite y de Armas (2015).

Una vez se hayan integrado los ejes verticales con los ejes horizontales ha llegado el momento de construir los componentes curriculares, los que serán básicos, profesionalizantes (optativos y electivos) e integradores, de acuerdo con el eje de origen. 
TABLA $\mathrm{N}^{\circ} 8$

Conceptos que intervienen en la construcción los componentes curriculares

\begin{tabular}{|c|c|}
\hline Conceptos & Definiciones \\
\hline $\begin{array}{l}\text { Los componentes } \\
\text { curriculares básicos }\end{array}$ & $\begin{array}{l}\text { Son aquellos que desarrollan los contenidos que serán la base para el dominio de los } \\
\text { componentes curriculares propios de la profesión y que se integran en un eje } \\
\text { curricular. }\end{array}$ \\
\hline $\begin{array}{l}\text { Los componentes } \\
\text { curriculares } \\
\text { profesionalizantes }\end{array}$ & $\begin{array}{l}\text { Son aquellos cuyos contenidos profundizan los conocimientos, habilidades y } \\
\text { destrezas propias del ejercicio de la profesión y aportan al desarrollo de las } \\
\text { competencias específicas. }\end{array}$ \\
\hline $\begin{array}{l}\text { Los componentes } \\
\text { curriculares } \\
\text { integradores }\end{array}$ & $\begin{array}{l}\text { Son aquellos que desarrollan la práctica laboral investigativa y el vínculo universidad } \\
\text { - sociedad, articulando los aprendizajes del semestre o del año. En estos se evidencia } \\
\text { el nivel de las competencias alcanzado por el estudiante, por lo que es necesario } \\
\text { implementar estrategias de aprendizaje integradoras. En estos componentes } \\
\text { curriculares, se desarrollará la práctica laboral investigativa, operativizando así las } \\
\text { funciones docencia, investigación y extensión en la carrera. Estos componentes } \\
\text { curriculares pertenecen al eje vertical integrador y tienen asignado el mayor número } \\
\text { de créditos en el semestre }\end{array}$ \\
\hline $\begin{array}{l}\text { Componentes } \\
\text { curriculares } \\
\text { optativos }\end{array}$ & $\begin{array}{l}\text { Son aquellos que el estudiante debe desarrollar de entre una serie de componentes } \\
\text { curriculares ofertados en el pensum de la carrera. Deben integrarse en los semestres } \\
\text { superiores de la carrera (a partir del séptimo semestre). Estos forman parte de los ejes } \\
\text { verticales profesionalizantes y responden a aquellos contenidos emergentes en los } \\
\text { campos de acción de la profesión. Por lo tanto, la Comisión Curricular de Carrera y } \\
\text { los colectivos de académicos definirán el número de estos componentes curriculares } \\
\text { relacionados con los campos de acción declarados y conectadas con el avance de la } \\
\text { ciencia. }\end{array}$ \\
\hline $\begin{array}{l}\text { Los componentes } \\
\text { curriculares } \\
\text { electivos }\end{array}$ & $\begin{array}{l}\text { Son aquellos que complementan la formación del estudiante sin que necesariamente } \\
\text { sean componentes curriculares de su formación disciplinar. Cada facultad podrá } \\
\text { ofertar componentes curriculares electivos, según las necesidades de formación de } \\
\text { sus estudiantes, las cuales deberán ser seleccionadas de su oferta académica } \\
\text { semestral. Para este efecto, la facultad deberá elaborar un catálogo. Estos estarán } \\
\text { abiertos a todos los estudiantes de la Universidad durante el semestre. } \\
\text { Los componentes curriculares electivos también se relacionan con los temas } \\
\text { transversales (formación integral) que se abordan en los ejes transversales. Estos } \\
\text { componentes curriculares son requisitos de graduación y el estudiante podrá tomarlos } \\
\text { en cualquiera de los semestres durante el tiempo de su formación. }\end{array}$ \\
\hline
\end{tabular}

Fuente: tomado de Sampaio, Leite y de Armas (2015).

\subsubsection{Organización de las prácticas laborales investigativas}

Todas las carreras deben contemplar prácticas laborales investigativas, independientemente de la modalidad de estudio.

De acuerdo con la naturaleza de las carreras y contexto, estas prácticas pueden ser internas o externas. Las prácticas internas son aquellas que se desarrollan en los ejes integradores y dentro de la Universidad. Para ello, se pueden emplear estrategias curriculares como resolución de problemas, proyectos, simulaciones, entre otras que abonen al desarrollo de las competencias. Estas se pueden desarrollar en los primeros años de formación.

Por su parte, las prácticas externas se desarrollarán en los años superiores de formación, una vez que los estudiantes hayan alcanzado un nivel de competencia que les permita desempeñarse en los diferentes ámbitos de actuación.

Para realizar las prácticas externas, las carreras harán uso de convenios (firmados por la máxima autoridad de la institución) y colaboraciones formalizadas con la red de instituciones públicas y privadas, y centros 
de investigación. Para ello, los responsables de ejes integradores deben ser especialistas o expertos en los diferentes campos de acción de la profesión.

\subsubsection{Modalidad de graduación}

Las modalidades de graduación son actividades integradoras del aprendizaje del estudiante y permiten la comprobación del desarrollo de las competencias. Además, estas deben estar vinculadas con las líneas de investigación y los campos de acción de la profesión, los cuales se relacionan con situaciones problémicas que el profesional deberá enfrentar y solucionar en la vida real.

Para que los estudiantes puedan finalizar su modalidad de graduación, debe haber aprobado todos los componentes curriculares de su plan de estudios y presentarse a la prueba de verificación de competencias.

Esta puede consistir en un trabajo de investigación que resulte de la sistematización del trabajo realizado en los ejes integradores, que incluye el desarrollado en las prácticas laborales investigativas; o la asignación de un problema propio de su profesión que la sociedad demanda su resolución. El estudiante debe resolverlo en un tiempo establecido (un semestre como máximo), y presentado ante un tribunal examinador. Esta permitirá conocer el nivel de logro alcanzado sobre las competencias genéricas y las específicas de su profesión.

\subsubsection{Evaluación por competencias}

La evaluación de competencias es la referencia que orientan el proceso de aprendizaje hacia el logro de las competencias. Por ello, ayuda a cualificar de manera objetiva -reduciendo las subjetividades- el desarrollo alcanzado por los estudiantes en relación con los objetivos de aprendizaje y las competencias.

La evaluación de las competencias tiene varias aristas: saber, saber hacer, saber ser, saber convivir, entre otras. Todas tienen que considerarse para poder certificar que el estudiante ha logrado un nivel de competencia determinado. Por tanto, la valoración del nivel de competencia alcanzado es cualitativa y se relaciona tanto con los objetivos de aprendizaje, los componentes curriculares básicos, profesionalizantes e integradores y con el eje transversal

Los elementos que se requieren para la evaluación son los siguientes:

- Los criterios que guían el juicio evaluativo. Estos permiten desagregar las competencias desarrolladas en diferentes niveles de profundidad.

- La matriz de evaluación (rúbricas) relacionada con el contenido de las evidencias, en términos de indicadores, descriptores y niveles de desarrollo de las competencias.

Los criterios de evaluación son afirmaciones explícitas del desempeño de los estudiantes. Estos describen niveles de éxito dentro del proceso de aprendizaje. Son componentes de los criterios de evaluación:

- Lo que se evalúa, es decir los resultados de aprendizaje (objetivos de aprendizaje), que evidencian el desarrollo de las competencias en los estudiantes, y que se relacionan con los objetivos de aprendizaje que tiene cada componente curricular o componentes curriculares.

- Con lo que se compara, es decir las evidencias explicitadas por medio de indicadores y descriptores que caracterizan el desarrollo de las competencias.

Para evaluar los aprendizajes de forma gradual y creciente en complejidad, es necesario tomar en cuenta los objetivos de los componentes curriculares, las competencias de la carrera y los elementos de la competencia, que no son más que un conjunto de atributos (conocimientos, valores, habilidades y actitudes) para el desempeño del sujeto acorde al nivel de estudio que cursa. Para ello es preciso elaborar una matriz o rúbrica de evaluación que integre los indicadores principales de los cortes evaluativos integradores. 
Tanto los componentes básicos, profesionalizantes e integradores deben integrar la evaluación de los ejes transversales: competencias genéricas, temas transversales y valores de manera explícita durante todo el período de formación.

\subsection{Política de investigación e innovación}

\subsubsection{Principios}

Los principios expresados en el documento Política de Investigación e Innovación (2017), son pertinentes para sustentar el Modelo de Continuidad de Formación de Grado en Posgrado. No obstante, se retoman aquellos que más se relacionan con esta, sin menos cabo de la vigencia de las políticas antes referidas, las que son aplicables a todos los procesos de investigación que se desarrollen en la UNAN - Managua:

- Fortalecimiento de capacidades de investigación e innovación:

- La UNAN - Managua garantiza la formación y la actualización permanente de docentes y estudiantes en materia de investigación.

- Los planes curriculares de grado y posgrado, implementan nuevas metodologías en los procesos de investigación, según los recursos anuales.

- Formulación de líneas de investigación e innovación:

- Se formulan en función de las necesidades y prioridades académicas y del contexto socioeconómico del país.

- Se actualizan previa evaluación.

- Conformación de grupos de investigación:

- La universidad promueve la formación de grupos de investigación multi, inter y transdisciplinarios.

- Los grupos de investigación están inscritos en el Vicerrectorado de Investigación para la validación de su actividad investigativa

- Toda actividad académica - investigativa de los grupos será registrada en el Vicerrectorado de Investigación.

- Los grupos de investigación asumen sus propias estrategias de gestión y de financiación de proyectos, respetando los procedimientos administrativos de la universidad.

- La divulgación y socialización de los resultados de investigación que se genere en los grupos de investigación será registrado en el Vicerrectorado de Investigación.

- Divulgación y socialización de la investigación:

- Debe ser permanente en la institución.

- Se realiza por medio de revistas (los correspondientes consejos editoriales velarán por los estándares de calidad), boletines electrónicos y otros medios digitales; a través de eventos académicos nacionales e internacionales: jornadas universitarias de desarrollo científico, congresos científicos, congresos de investigación, innovación y emprendimiento; foros, simposios, paneles, mesas redondas, seminarios entre otros.

- Ética en la investigación:

- Docentes y estudiantes son libres para seleccionar el tema de su investigación dentro de las líneas de investigación definidas por la universidad.

- Los resultados de investigación deben estar disponibles para la revisión y la crítica. 
- Las investigaciones deben ser auténticas, evitando el plagio de otros estudios realizados en el país o en el extranjero.

- Las técnicas y resultados de investigación deben ser reñidos por la ética científica y profesional. Por tanto, deben cuidar derechos humanos relacionados con la salud, seguridad, privacidad y otros derechos que violen la libertad o lesionen tanto al ser humano como a animales.

\subsubsection{Lineas de investigación [1]}

En este apartado, se exponen los principales conceptos y criterios relacionados con las líneas de investigación definidas por la UNAN - Managua. Por ello, se parte de la definición construida en el documento "Líneas de investigación de la UNAN-MANAGUA (junio de 2020)":

Línea de Investigación: Es una directriz institucional de nivel estratégico, sustentada desde un área amplia del conocimiento, que articula los macro procesos de formación, investigación y extensión, en función de la aplicación, creación y difusión del conocimiento científico, para contribuir a la resolución de problemas locales, nacionales y regionales. (p.3)

La definición anterior se construyó a partir del concepto línea de investigación adoptado por el Consejo Nacional de Evaluación y Acreditación (CNEA) y considerando el principio planteado en el documento "Políticas de Investigación e Innovación de la UNAN-Managua" (2017):

Es un constructo multidimensional de la gerencia de la investigación en relación a cuerpos de conocimiento científicos. Es una estrategia gerencial diseñada para estimular y coordinar la actividad investigativa institucional, y en cuyo desarrollo se procura alcanzar la excelencia académica y producir un impacto positivo en entornos determinados, sirviendo como eje ordenador, orientador y organizador de planes de acción, garantizando al máximo la eficiencia en el logro de las metas previstas y del desarrollo permanente (De Nazaret, de Meza y Meza, 2010) citado en CNEA (2019).

Las líneas de investigación (...) se formulan y se actualizan previa evaluación, en función de las necesidades y prioridades académicas y del contexto socioeconómico del país, reflejado en el Plan Nacional de Desarrollo Humano (PNDH) de Nicaragua (p. 5). ("Políticas de Investigación e Innovación de la UNAN-Managua" (2017))

La definición de las líneas de investigación se realizó con base en dos tipos de criterios que responden a procesos diferentes: construcción y validación. En relación con el momento de construcción, los criterios de consistencia aplicados fueron:

- Productividad: Hace referencia tanto a la cantidad como a la calidad de los productos que se han obtenido y puedan obtenerse a partir de los programas y proyectos institucionales relacionados con la línea de investigación.

- Continuidad: La línea de investigación debe ser lo suficientemente amplia, de tal forma que tenga posibilidad de subsistir en el tiempo. Para esto, debe tenerse claro tanto el estado del arte del objeto de estudio relacionado con la línea de investigación, como sus retos, desafíos y tendencias.

- Articulación: La línea debe poder articular el trabajo de la investigación con el quehacer de la formación y la extensión. En este sentido, se constituye como un eje central para la planificación y desarrollo del quehacer académico de la Universidad.

(Líneas de investigación de la UNAN-MANAGUA (junio de 2020, p.3))

En relación con el proceso de validación -revisión, refinamiento y mejora de las Líneas y Sub Líneas de Investigación- por parte de distintas entidades externas, entre las que destacan Ministerios, Institutos y otras instituciones de gobierno relacionadas con el trabajo que se realiza desde las distintas áreas del conocimiento de la Universidad, se utilizan tres criterios: 
- Pertinencia: ¿La línea o sub línea de investigación responde a problemas del contexto nacional y regional?

- Vinculación: ¿La línea o sub línea de investigación permite establecer y dar continuidad al trabajo entre la Universidad y la Entidad a la cual usted representa?

- Suficiencia: ¿La línea o sub línea de investigación aborda aspectos esenciales del quehacer de la Entidad a la cual usted representa?

(Líneas de investigación de la UNAN-MANAGUA (junio de 2020, p.5))

Además, de los criterios establecidos para la construcción, se tomaron como referentes los ODS y dos principios generales que confieren amplitud y soporte a cada línea de investigación (Líneas de investigación de la UNAN-MANAGUA (junio de 2020, p.3)):

- Se deben tomar como referencia los "Ejes del Programa Nacional de Desarrollo Humano 2018 2021" y los Objetivos de Desarrollo Sostenible (ODS)\#

- Las Líneas de Investigación deben ser lo suficientemente amplias, no deben centrarse en una carrera, departamento o unidad académica particular. Deben hacer alusión al objeto de estudio y orientar sobre su derivación en posibles sub líneas.

- Las Líneas de Investigación deben cumplir con los Criterios de Consistencia y los de Soporte, o en su defecto, establecerse un plan a corto o mediano plazo para su cumplimiento.

En relación con los criterios de soporte, en términos de evidencias que aportan datos sobre la productividad de las líneas de investigación que se desarrollen en grado y posgrado, se consideraron las siguientes:

- Publicaciones (ensayos, artículos, libros, capítulos de libros).

- Ponencias y presentaciones de poster en eventos científicos.

- Tesis de grado y posgrado.

- Grupos de Investigación o redes de trabajo.

- Capacidad instalada (recursos humanos, infraestructura y equipos).

- Proyectos de investigación.

Es necesario destacar, que las líneas de investigación definidas, también responden a dos dimensiones: prospectiva y teleológica. Estas proyectan, con visión clara de lo necesario y de lo posible, las metas imperantes, demandadas desde dos grandes marcos de acción: Los Objetivos de Desarrollo Sostenible (ODS) y el Plan Nacional de Desarrollo Humano (PNDH) de Nicaragua. La eficacia y la eficiencia que ambas dimensiones confieren a las Lineas de Investigación definidas favorece la planificación estratégica y la oportunidad imperante de articular y cohesionar de manera sinérgica el trabajo de la formación, la investigación y la extensión de grado, posgrado y programas especiales.

El éxito en el desarrollo de estas Líneas de Investigación, requiere del fortalecimiento de una cultura organizacional que considere el quehacer académico desde una visión integral, como bien señalan Katz \& $\operatorname{Kahn}(1989$, p. 163):

La dicotomía entre enseñanza e investigación, como funciones diferentes, es una división más práctica que lógica. Parte del mejor adiestramiento y de la mejor enseñanza ocurre en el laboratorio de investigaciones; y aquellas universidades donde se hace mucho hincapié en la enseñanza, olvidando la investigación, pronto terminan siendo lugares muertos, incluso para la enseñanza.

De ahí que las Líneas de Investigación constituyen el principal referente para el trabajo conjunto de las Facultades, Institutos, Centros y Laboratorios de Investigación, y proporcionan la base para el establecimiento de relaciones interinstitucionales.

Las Líneas de Investigación por Áreas de Conocimiento de la UNAN-Managua, esfuerzo que en este “2020: año de la Educación con Calidad y Pertinencia” cobra especial relevancia, en el marco de los procesos 
encaminados a la acreditación internacional de nuestra Universidad, así como de los procesos relacionados con el Perfeccionamiento Curricular. Por ello, las líneas definidas por la Universidad tienen como base las áreas del conocimiento determinadas por el Vicerrectorado de Docencia, las que se basan en las áreas propuestas por el Consejo Nacional de Evaluación y Acreditación (CNEA):

- Ciencias Sociales y Humanísticas.

- Ciencias de la Educación.

- Ciencias Naturales y Exactas.

- Ingeniería, Industria y Construcción.

- Salud.

- Ciencias Económicas.

- Ciencias Agropecuarias.

Considerando las áreas de conocimiento en la UNAN - Managua se han definido 17 líneas de Investigación. De estas se derivan y operativizan sublíneas (documento borrador Lineas de investigación de la UNAN-MANAGUA. (2020)), que a su vez deberán concretizarse en temas de investigación, asumidos por los distintos programas y proyectos de investigación de la Universidad.

Estos programas y proyectos deben planificarse por grupos de investigación (docentes, estudiantes y personal administrativo), en función del cumplimiento de la misión socialmente encomendada a la Universidad: "Formar profesionales integrales, con dominio de las competencias ciudadanas y científicotécnicas que demanda el pueblo nicaragüense, así como generar conocimientos, para aportar al desarrollo político, económico y social sostenible del país".

\subsection{Extensión universitaria [2]}

La extensión universitaria: “(...) promueve la identidad cultural que conjuntamente con la Investigación, la Docencia, la Internacionalización y la Gestión Universitaria constituyen los pilares básicos sobre los que se construye un Modelo de Universidad comprometida socialmente en la búsqueda de la excelencia, pertinencia y equidad". (Política de extensión universitaria 2017-2019.(2017.p. 9)). El concepto de extensión pone de manifiesto la responsabilidad de la universidad en relación con la sociedad nicaragüense, por ello extiende su actuación educativa hacia los diferentes sectores del país para fortalecer su quehacer mediante la cooperación e intercambio con estos (Plan estratégico institucional 2015 - 2019. (2015)).

Lo subrayado anteriormente está en consonancia directa con la idea base sobre extensión universitaria del Consejo Nacional de Universidades (CNU) (2016):

La presencia e interacción académica mediante la cual la Universidad aporta a la sociedad -en forma crítica y creadoramediante sus resultados y logros de su investigación y docencia por medio de la cual, al conocer la realidad nacional, enriquece y dimensiona toda su actividad académica conjunta. Resaltando dos principios generales de esta (...) la pertinencia y responsabilidad, cumpliendo un rol de formación continua de la propia comunidad universitaria en su conjunto, un rol divulgación científica (sic) y de la diversidad cultural, un rol en la transformación social y desarrollo comunitario y un rol en la transferencia tecnológica, con visión estratégica del desarrollo. (Política de extensión universitaria 2017 - 2019. (2017.p. 9))

Para esta estrategia se retoman tres áreas en las cuales la extensión universitaria concentra su mayor expresión, por tanto, son el foco ideal para desarrollar la docencia con el enfoque por competencias adoptado por la universidad y las líneas de investigación construidas. Es decir, con estas favorecen el fortalecimiento del vínculo entre los procesos formación, investigación y extensión, dando la oportunidad a que los colectivos de académicos y estudiantes de grado y posgrado realicen prácticas de formación profesional y a la vez desarrollen proyectos de investigación: 
- Investigación, desarrollo e innovación: promueven el emprendimiento, la propiedad intelectual, la investigación científica y la gestión del conocimiento tanto a nivel nacional como internacional, con el fin de fortalecer los procesos de investigación bajo la concepción de desarrollo social, técnico y económico.

- Prácticas: fomentan en los estudiantes de grado y posgrado el desarrollo de experiencias de carácter económico, social y ambiental en instituciones públicas, privadas y ONG, de tal manera que con su formación académica y profesional.

De acuerdo con la Normativa de Prácticas y Pasantías (2020) se realizarán, según la titulación correspondiente (Técnico Superior, Licenciatura o su equivalente y medicina). Las Prácticas de Formación Profesional comprende dos etapas:

La PFP preprofesional comprende:

- la etapa de familiarización que tendrá la duración de un mes, en acuerdo con el plan establecido tanto por la empresa, institución u ONG y la carrera correspondiente.

- la etapa de especialización iniciará una vez concluido el mes de familiarización y finalizará de acuerdo con el semestre correspondiente, tomando en cuenta la planificación realizada entre la empresa, institución u ONG y la carrera correspondiente.

La PFP de profesionalización durará un semestre de acuerdo con la planificación establecida por la empresa, institución u ONG y la carrera correspondiente. Se podrá extender por un semestre más, de acuerdo con los requerimientos de las instituciones, empresas y ONG. Cuando la PFP se extienda más allá del semestre contemplado, por el plan de estudios de la carrera, esta será considerada como una pasantía.

Las acciones generales de esta área son:

- Integración de la teoría con la práctica en contextos reales donde se potencie de manera creativa las competencias profesionales de los estudiantes.

- Creación de espacios de aprendizaje para que el estudiante analice, comprenda e interprete la realidad desde sus conocimientos (competencias) a fin de contribuir a solucionar situaciones problémicas en diferentes contextos de actuación profesional y personal.

- Ofertar servicios a la sociedad con conocimiento actualizado con valores éticos y con responsabilidad social.

- Documentación de experiencias desarrolladas entre la Facultad - Estudiante -Institución, Empresa u ONG, que permita la generación de nuevos conocimientos útiles a la Universidad y a la Sociedad.

- Programas y proyectos: se interesa por la formulación, gestión y ejecución de programas y proyectos en los que se involucren docentes - investigadores y estudiantes con el fin de ayudar a superar problemáticas sociales.

Son acciones generales de esta área:

- Articulación de los procesos de investigación, docencia y extensión en una acción conjunta, coherente y cohesionada, a fin de fomentar una relación estrecha entre la universidad y la sociedad.

- Sistematización de las experiencias desarrolladas en programas y proyectos para el desarrollo de nuevos saberes científicos y técnicos, así como su devolución a la sociedad. 
- Instauración de servicio comunitario como medio de formación y devolución de profesionales con responsabilidad social, éticos y con calidad que contribuyan con el bienestar de la población en especial de los sectores menos favorecidos.

- La medición del impacto social que se genera con los programas y proyectos en los que se vinculan, la docencia, la investigación y la extensión.

\section{Conclusiones}

Finalmente, se puede concluir que el modelo para lograr la integración de grado en posgrado es necesario para el desarrollo académico-científico de la UNAN-Managua, por ello es necesaria una cultura que lo favorezca y permita a sus recursos humanos visualizarlo de manera clara y posible. Ante esto, la esquematización del modelo sintetiza la manera en que se debe dimensionar desde los diferentes actores involucrados en este proceso de mucha complejidad, no obstante, alcanzable.

\subsection{Integración de la formación de grado y posgrado}

La representación esquemática de la integración de la formación de grado y posgrado es necesaria para la comprensión del modelo. En esta se logra observar cómo los tres procesos formación, investigación y extensión se convierten en componentes centrales para lograr la vinculación de sí mismos, a través de varios elementos derivados del modelo para desarrollar competencias, las políticas de investigación y de las políticas de extensión.

En los siguientes esquemas, se visualiza la coherencia en los tres niveles de integración y vinculación entre los componentes de la estrategia: a) nivel de integración en la carrera de grado, b) nivel de integración en el eje integrador, proyectos de investigación (de intervención) y c) nivel de integración y vinculación con posgrado.

En el primer nivel, se parte de los problemas que son internos de la institución o externos a la institución (sociales). Estos son identificados por las carreras de grado las cuales desde su formulación deben tener claros qué programa director y qué proyectos de investigación debe construir a fin de ayudar a resolver las problemáticas identificadas. Por ello, tiene un objeto de estudio y un perfil de egreso que le permite tener tanto docentes - investigadores como estudiantes capacitados (con las competencias necesarias), para lograr de manera efectiva indagar sobre la realidad y aportar soluciones pertinentes a las situaciones presentadas desde las líneas y sublíneas de investigación correspondientes. 


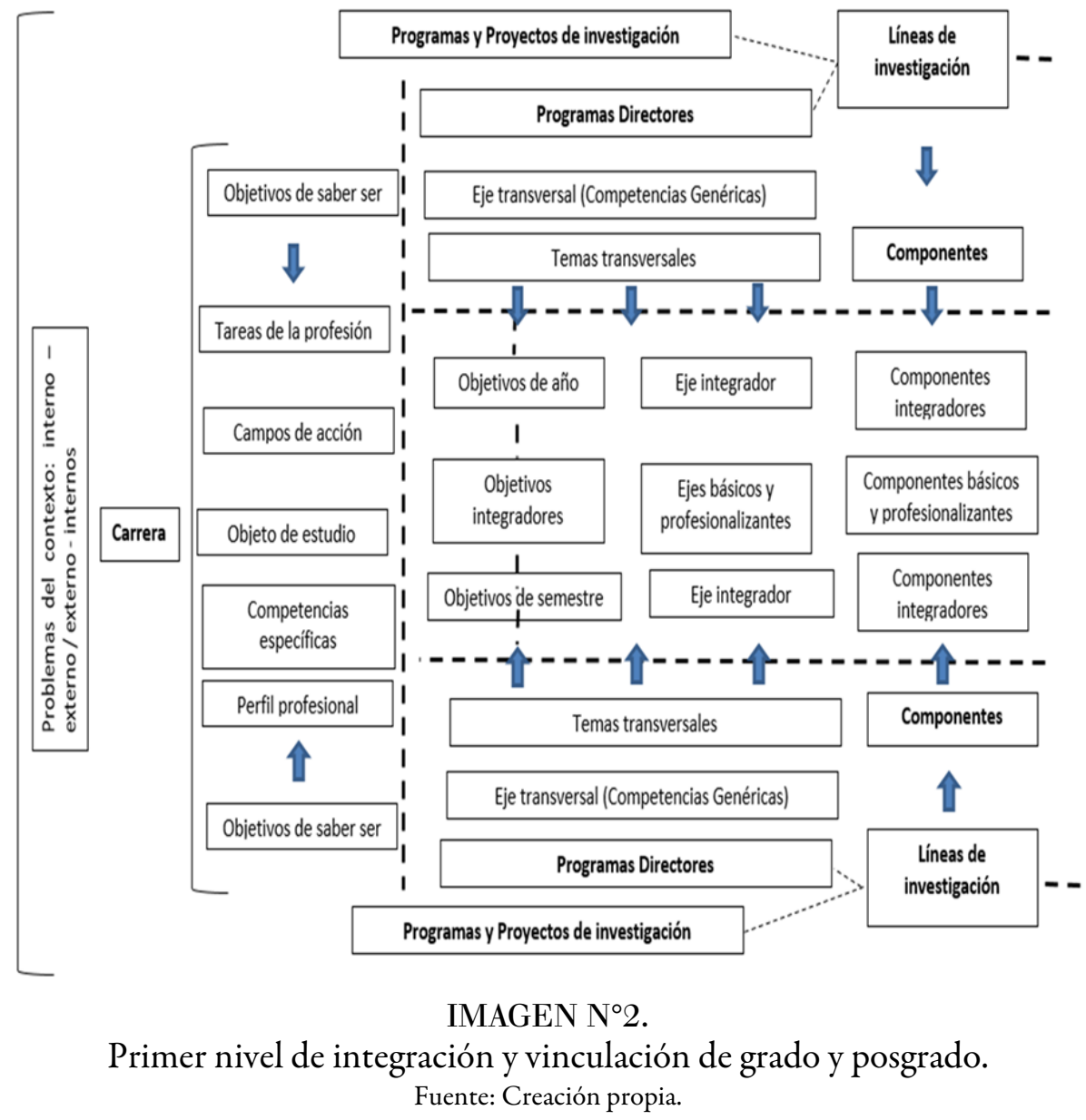

En el segundo nivel, a lo interno de las carreras, las líneas de investigación, que tienen relación con los problemas contextuales, se desarrollan desde los componentes curriculares integradores, las prácticas de formación preprofesional y las prácticas de investigación profesional. Además, se desarrollan desde los proyectos de intervención social, que deben permitir la investigación y el desarrollo de prácticas para los docentes - investigadores y los estudiantes. En este nivel, ya se puede observar la presencia de los grupos de investigación que pueden desarrollar sus planes de trabajo en los componentes integradores, las prácticas de formación profesional, los programas directores y proyectos de investigación relacionados con su ámbito de actuación y ámbitos de otras profesiones. 


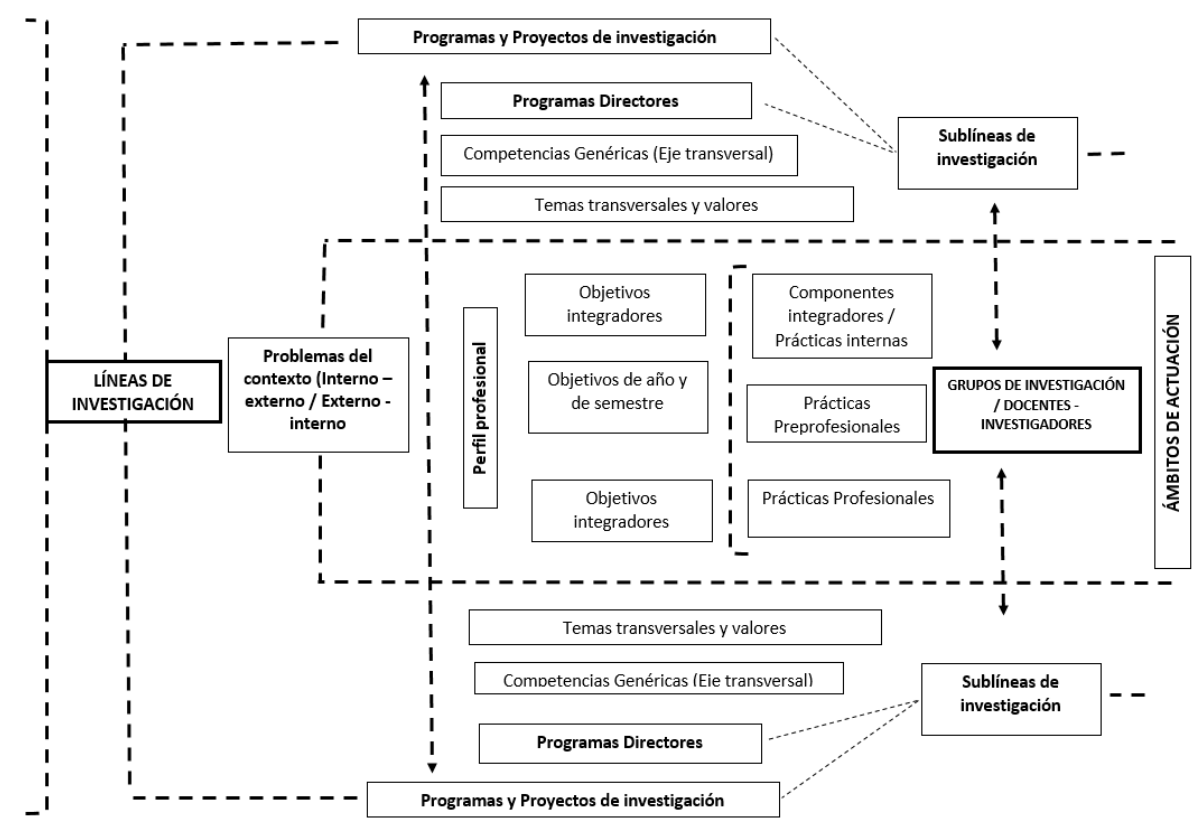

IMAGEN N`3.

Segundo nivel de integración y vinculación de grado y posgrado.

Fuente: Creación propia.

En el tercer nivel, los problemas contextuales han recibido atención desde las carreras de grado (memorias de investigación de los estudiantes como modalidad de graduación y prueba de que han alcanzado las competencias). Las competencias se proyectan hacia posgrado, ganando profundidad en los desempeños por lograr y en el alcance en relación con la formación científica, necesaria para aportar soluciones a las problemáticas científicas, sociales y técnicas con mejor conocimiento. Los grupos de investigación (docentes - investigadores, maestrantes y doctorantes), se organizan en redes científicas y educativas interdisciplinares o transdisciplinares, que favorecen su actuación y la generación de nuevo conocimiento científico y técnico. Además, se profundiza en el desarrollo (productividad) de las líneas y sublíneas de investigación en relación con el avance de las ciencias y en los aportes que ayuden a solucionar problemáticas complejas de la sociedad desde diferentes programas de posgrado. 


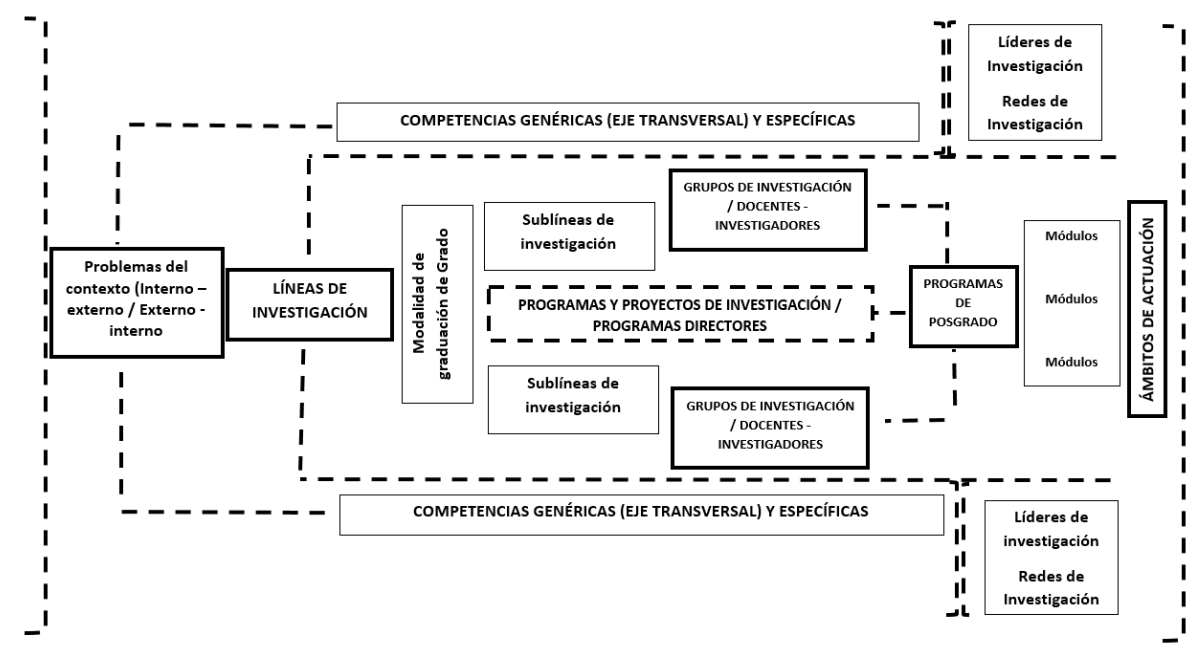

IMAGEN N4.

Tercer nivel de integración y vinculación de grado y posgrado.

Fuente: Creación propia.

La conjunción de los tres niveles da como resultado la visión completa sobre cómo ocurre la integración y la vinculación de las competencias genéricas, las competencias específicas y las líneas de investigación tanto en las carreras de grado como su continuidad y profundización hacia los programas de posgrado. En relación con la integración y vinculación de las líneas de investigación, las carreras de grado lo hacen considerando las posibilidades que ofrece el modelo para desarrollar competencias: en los componentes integradores, en componentes de metodología de investigación, en las prácticas preprofesionales y profesionales, de manera transversal, en programas directores y en proyectos de intervención (investigación) en los que se desarrollen procesos de aprendizaje relacionados con los procesos de formación, investigación y extensión.

Para de Armas (2020) la continuidad de grado en posgrado se termina de concretizar mediante el siguiente proceso:

- a. Preparación de las comisiones de carrera

- Las comisiones preparan los programas de pregrado y grado

- Las comisiones predefinen los programas y la posible continuidad de estudio

- Las comisiones proponen la continuidad de estudio a nivel de especialidades, maestrías y doctorado

- Las comisiones defienden el plan para su aprobación en el Consejo

- b. Vinculación de las carreras con las líneas de investigación establecidas

- c. Proyectos de investigación asociados a carreras

- d. Elaboración de los programas

- Diseño de programas: estructura e indicadores

- Se elaboran los programas de especialidades

- Se elaboran los programas de maestría que dan continuidad de estudio

- Se elaboran los programas de doctorado

- e. Se crean los grupos de investigación que desarrollan las líneas y proyectos de investigación que tributan al desarrollo de los programas en cuanto a su eje integrador.

- f. Preparación general de los colectivos docentes para la implementación

- g. Evaluación de la calidad de los programas implementados

- h. Perfeccionamiento o mejora continua de los programas. 
Cada uno de los pasos propuestos, se visualiza en el esquema que completa el modelo para la continuidad de la formación de grado en posgrado:

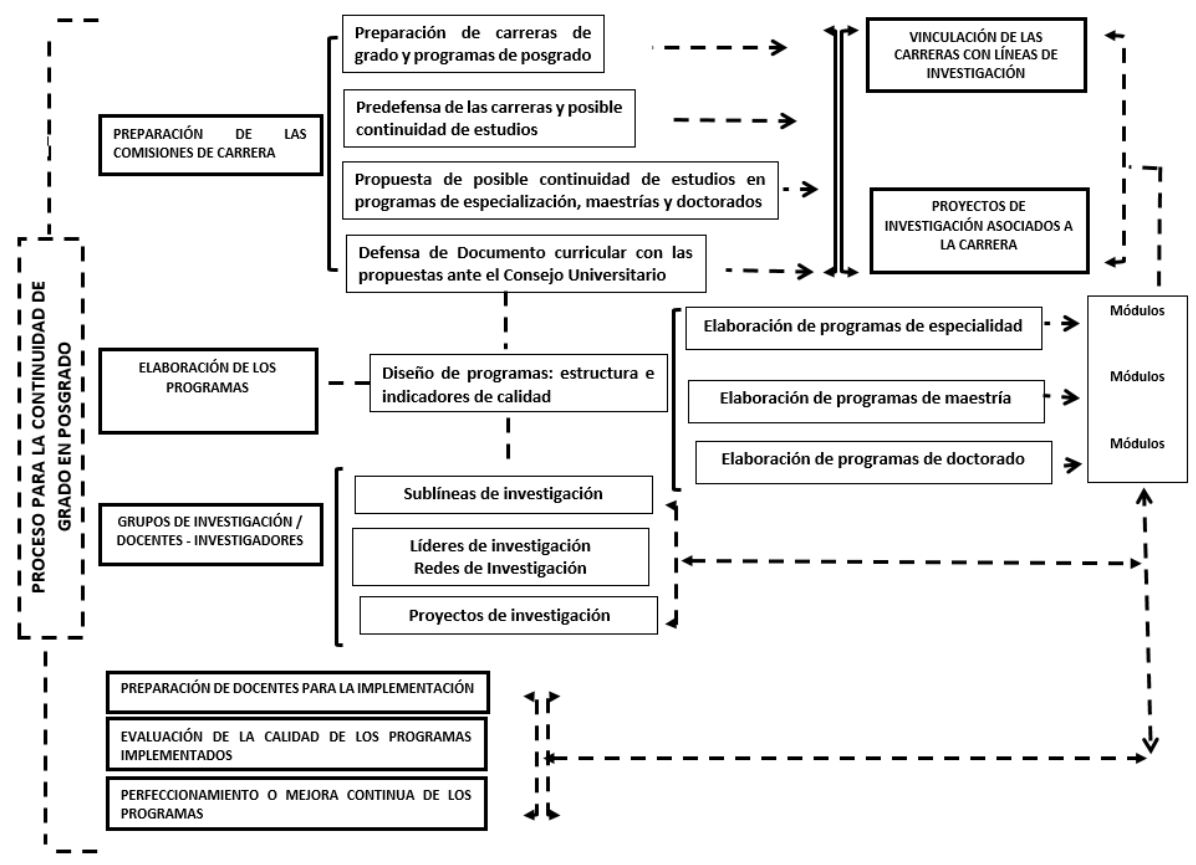

IMAGEN N5.

Proceso final para concretizar la continuidad de grado y posgrado.

Fuente: Creación propia.

Con las acciones anteriores termina el proceso de continuidad y da inicio el de formación en posgrado, en este entran en acción los estudiantes y los profesores. Así la planificación y ejecución que da salida al proceso de implantación del currículo es organizado, aprobado y evaluado por posgrado.

\subsection{Ejes para el acompañamiento y la evaluación del modelo}

Finalmente, el MODELO PARA LA CONTINUIDAD DE LA FORMACIÓN DE GRADO EN POSGRADO: UNAN - MANAGUA, debe tener el acompañamiento correspondiente, por tanto, se plantean los siguientes ejes para lograr la evaluación de este, con fines de mejora:

\subsubsection{Construcción colectiva de la innovación curricular:}

- Coordinación del trabajo de equipo $(s)$

- Objetivos en común

- Análisis de fortalezas y oportunidades para la mejora continua del trabajo en equipo

- Gestión del conocimiento para la participación de los actores en la mejora curricular:

- Del aprendizaje

- De la información: documentos curriculares, normas, manuales, informes de investigación, informes de sistematización entre otros

- De la colaboración 


\subsubsection{Currículo para desarrollar competencias:}

- Campos de acción

- Ámbitos de actuación

- Objeto de estudio de la profesión

- Competencias genéricas y específicas

- Perfil profesional

- Objetivos de aprendizaje por niveles (anuales, semestrales, integradores y transversales)

- Ejes disciplinares curriculares verticales, horizontales, integradores y transversales (competencias genéricas, temas transversales y valores)

- Componentes curriculares

- Prácticas de formación profesional

- Modalidad de graduación en términos de prueba de verificación de competencias

- Evaluación por competencias

\subsubsection{Formación docente:}

- Implantación del curriculum

- Integración del trabajo docente

- Elaboración de material didáctico y de apoyo para la formación permanente de docentes

- Capacitación: estrategias metodológicas y evaluación por competencias

\subsubsection{Continuidad de formación:}

- Perfil de salida de grado y perfil de ingreso a los programas de posgrado

- Armonización de horas y reconocimiento de créditos

- Articulación de niveles, ejes disciplinares, ejes transversales y grados

- Integración y jerarquización de contenidos

- Atención a estudiantes con necesidades pedagógicas particulares

- Movilidad estudiantil y docente

\subsubsection{Integración en la formación de la investigación y la extensión}

- Líneas de investigación

- Grupos de investigación

- Redes de docencia e investigación

- Programas directores

- Proyectos de investigación y extensión

6.2.6. Evaluación de los procesos de construcción del curriculo, formación docente, continuidad de estudios, investigación y extensión:

- Investigación acción educativa como eje integrador de la gestión del currículum

- Acompañamiento pedagógico

- Asesoría 
- Evaluación el proceso de enseñanza - aprendizaje

- Evaluación del proceso de implementación del currículum

- Evaluación de la continuidad de formación de grado en posgrado

- Indicadores y criterios de calidad

\section{REFERENCIAS BIBLIOGRÁFICAS}

Aznar, F. (9 de agosto de 2017). Repensar el liderazgo estratégico. La visión -5ª-. Instituto Español de Estudios Estratégicos. $\mathrm{N}^{\circ}$. 42/17. p. 1-17.

Borrero, A. (1982). "La interdisciplinariedad”. Simposio Permanente sobre la Universidad. Primer Seminario General. Bogotá.

Bueno. E. et al. (1996). Dirección Estratégica de la Empresa. Metodología, Técnicas y Casos. Pirámide S. A.

Campbell, A. (1997). Mission Statements. Long Range Planning, Vol. 30, №, p.931.

Consejo Superior Universitario Centroamericano (CSUCA). (2018). Marco de Cualificaciones para la Educación Superior Centroamericana (MCESCA): resultados de aprendizaje esperados para los niveles técnico superior universitario, bachillerato universitario, licenciatura, maestría y doctorado. Serviprensa.

De Armas, R. (2020). Recomendaciones para la planificación estratégica en UNAN-Managua. Manuscrito.

Fontaines - Ruiz, T. y Martínez, J. (2015). Complejidad, epistemología y multirreferencialidad. Universidad Técnica de Machala.

García, S. y Dolan, S. (1997). La Dirección por Valores. McGraw. Hill.

González, J. (2013). El desarrollo de la cibercultura en proyectos de conocimiento: hacia una comunidad emergente de investigación. En Chávez, M. Covarrubias, K. y Uribe, A. (2013). Metodología de la investigación en ciencias sociales. Aplicaciones prácticas. Universidad de Colima.

González, M. Hernández, A. Hernández, H. y Sanz, T. (2003). Curriculum y formación profesional. Universidad de la Habana.

Hernández, I. et al. (2020). Proyecto Institucional UNAN - Managua. Editorial Universitaria UNAN-Managua.

Johnson, G. y Scholes, K. (2001). Dirección Estratégica. (5a edición). Pearson Educación.

Katz, D. y Kahn, R. (1989). Psicología Social de las organizaciones. Trillas.

Kotter, J. P. y Heskett, J. L. (1995). Cultura de empresa y rentabilidad. Ediciones Díaz de Santos, S. A.

Lahitte, H. Hurrei, J. y Malpartida, A. (1989). Relaciones 2. Crítica y expansión de la ecología de las ideas. Argentina: Ediciones Nuevo Siglo.

Lakatos, I. (1978) Metodología de los Programas de Investigación Científica. Siglo XXI Editores.

Martínez, H. (2010). Manual de investigación. La investigación como proceso en la universidad. Guatapuri Ediciones. Universidad de Santander.

Martos, R. (2009). Cultura Corporativa: Misión, Visión y Valores en la Gestión Estratégica de las empresas del sector de la Automoción en España. (Tesis de Doctorado). UNIVERSITAT POLITĖCNICA DE CATALUNYA

Morín, Edgar. (2010). Por un pensamiento del Sur. Instituto Peruano de Pensamiento Complejo Edgar Morin, 11.

Mullane, J. (2002). The mission statements is a strategic tool: when used properly. Management Decision.Vol.40/5, p. $448-445$

Ortiz, F. y Del pilar, M. (2007). Metodología de la investigación. El proceso y sus técnicas. Limusa S.A.

Sampaio, L. Leite, P. y De Armas, R. (2015). Diseño curricular para desarrollar competencias: una propuesta metodológica. Editorial Universitaria de Tiradentes.

Soler Vicente, C. (1996). La Cultura Organizativa y las estrategias de Recursos Humanos. Una visión Directiva. Facultat de Psicología. Universitat de Barcelona. 
Tamayo y Tamayo, M. (2004). El proceso de investigación cientifica: Incluye evaluación y administración de proyectos de investigación. Limusa.

Torres, J. (1987). La globalización como forma de organización del currículo. Revista Educación. №282. Enero/abril. pp. 103-130.

Universidad Nacional Autónoma de Nicaragua, Managua. UNAN - Managua. (2020). Líneas de investigación de la UNAN-MANAGUA. (Documento de trabajo). UNAN - Managua.

Universidad Nacional Autónoma de Nicaragua, Managua. UNAN - Managua. (2020). Normativa de Prácticas y Pasantías de la UNAN-MANAGUA. (Documento de trabajo). UNAN - Managua.

Universidad Nacional Autónoma de Nicaragua, Managua. UNAN - Managua. (2017) Politica de Investigación e Innovación. UNAN - Managua.

Universidad Nacional Autónoma de Nicaragua, Managua. UNAN - Managua. (2017) Política de Extensión Universitaria 2017 - 2019. UNAN - Managua.

\section{Notas}

[1] Acápite construido a partir de documento borrador Lineas de investigación de la UNAN-MANAGUA. (2020).

[2] Subapartado redactado a partir del documento Política de Extensión Universitaria 2017 - 2020. (2017). 